\title{
UNA ESTRATEGIA PARA LA VIABILIDAD DE LA REFORMA POLITICA
}




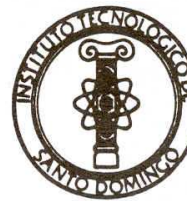

\section{ciencia
sociedad}

Volumen XXII, Número 1

Enero - Marzo 1997

Santo Domingo, Republica Dominicana

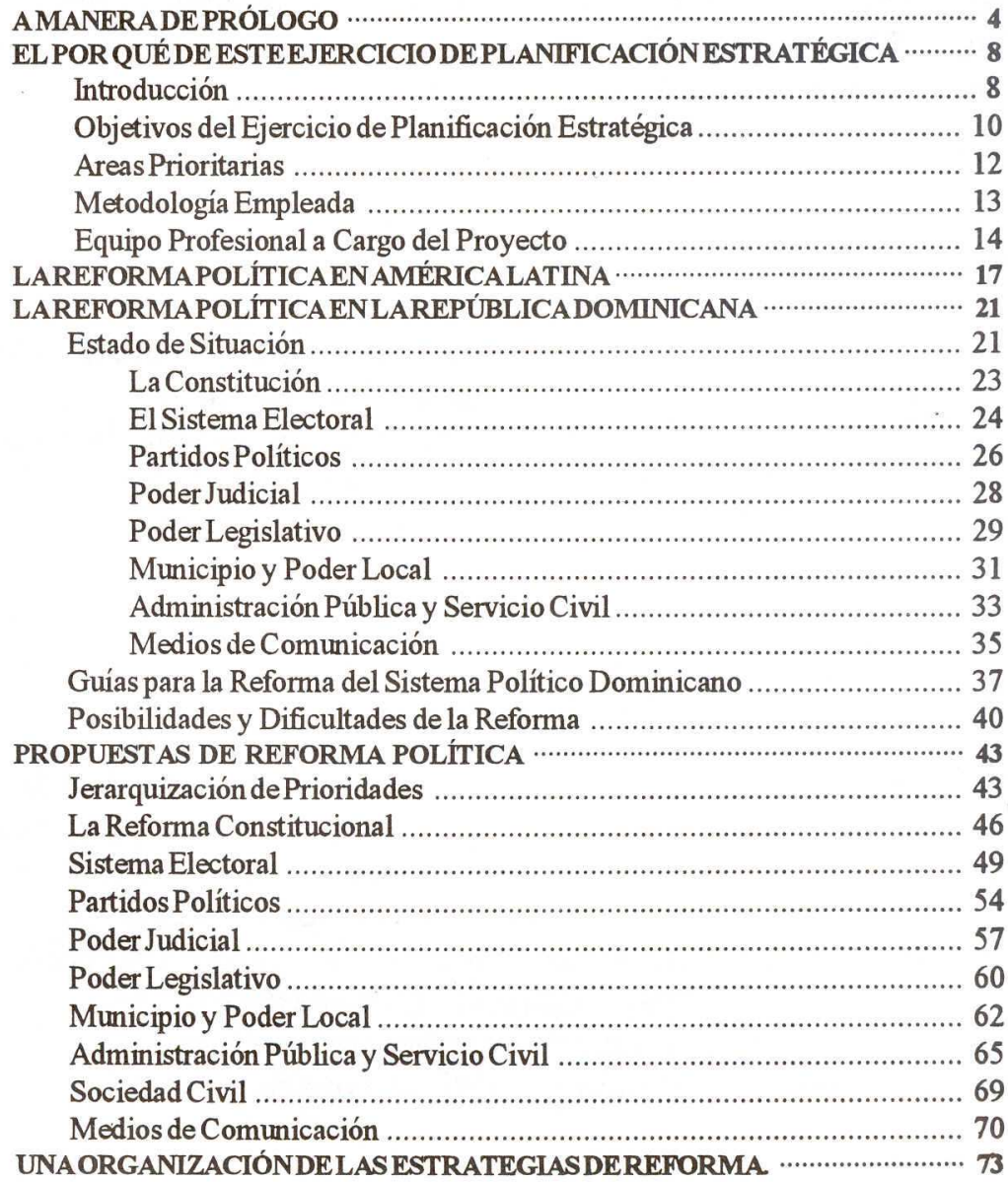


La organización, tanto política como administrativa, del Estado Dominicano de hoy refleja desgraciadamente una realidad histórica ampliamente superada. Está organizado para lo que fue, por lo cual resulta poco funcional para el presente. $Y$ si miramos al futuro, se puede decir que carecemos de un Estado preparado para enfrentar con posibilidades de éxito los retos y desafios que los nuevos tiempos nos imponen y que están concretizados en el fenómeno de la globalización.

La democracia, como forma de gobierno, aunque consagrada en nuestra Constitución y ejercitada formalmente mediante el voto de los ciudadanos, necesita legitimarse en relación a su contribución a la superación de los problemas políticos, sociales y económicos que aquejan a las grandes mayorías nacionales. Se puede afirmar sin exageración que, si no queremos correr el riesgo de perderla, nuestra democracia tiene que modernizarse - creciendo en eficacia y eficiencia- y convertirse de meramente representativa en real y verdaderamente participativa.

Por estas razones, la reforma del sistema político dominicano -incluyendo Estado, partidos políticos y sociedad civit además de necesaria, tiene carácter de urgencia. En primer lugar, pese a las dificultades que todo proceso de reforma política entraña, la reforma política viene siendo reclamada y defendida en los últimos tiempos por amplios sectores de la sociedad dominicana. A esto hay que sumar el compromiso público contraído por el actual Presidente de la República con el proceso de reforma y modemización del Estado. Este compromiso otorga a la reforma política el componente decisivo de "voluntad política", ausente por desgracia en gobiernos anteriores. Finalmente, se debe señalar que, además de existir un conocimiento generalizado 
de las reformas por realizar - existiendo hasta valiosas compilaciones de las mismas - se observa también un sorprendente nivel de consenso en torno a cuáles de ellas son las más prioritarias.

Sin embargo, aunque es cierto que hay conocimiento y consenso acerca de las reformas a realizar, todavía no se ha llegado a formular suficientemente el cómo lograr que esasreformas políticas sean aprobadas y puestas en ejecución. En otras palabras, nos ha faltado una estrategia que haga viables las reformas políticas consideradas como necesarias. Y ésta ha sido, precisamente, la finalidad del ejercicio de planificación estratégica para la reforma política que INTEC ha llevado a cabo recientemente y que ahora, por este medio, se hace público.

A fin de llevar a término ese ejercicio de planificación estratégica -que bien podría ser calificado de "experimento en ingeniería política"-INTEC identificó nueve áreas consideradas como prioritarias dentro de una reforma política para la República Dominicana de hoy. Para trabajar en ellas, se procedió en dos etapas. Primero, se conformaron nueve equipos de trabajo integrados por especialistas dominicanos e internacionales. Cada uno de los equipos produjo un reporte que cubría a profundidad la reforma en el área a él asignada. El aporte fundamental de esos trabajos fue presentar, para cada reforma estimada como prioritaria, la forma concreta - el cómo-de pasar de la mera formulación de una propuesta a lograr su puesta en práctica mediante la adopción de una serie de medidas estratégicas y tácticas. Segundo, una vez terminada esta labor fundamental, un equipo más reducido - seleccionado de entre los mismos especialistas- elaboró una recopilación sintética de los trabajos producidos para cada área de reforma por los equipos originales.

La presente publicación contiene ese documento-síntesis del ejercicio de planificación estratégica para la reforma política realizado por INTEC. Sumariamente expuesto, he aquí su contenido:

- A modo de diagnóstico actualizado, se presenta un "estado de situación" de cada una de las nueve áreas de reforma consideras como prioritarias.

— Se esboza una jerarquización de esas prioridades. 
- Luego, para cada reforma, se hacen recomendaciones; se señalan los aspectos a tomar en cuenta; y se sugieren estrategias a seguir, enumerando tanto los obstáculos que se oponen a su logro como las oportunidades que existen para su puesta en práctica.

- En los casos en que se prevén dificultades para que las reformas propuestas puedan realizarse tal y como fueron planteadas, se incluyen reformas alternativas de más fácil consecución.

- Finalmente, se presenta una organización de las estrategias para viabilizar las reformas propuestas, atendiendo al nivel de consenso logrado, su posibilidad de realización a corto plazo y su dependencia de una "voluntad política", bien para ejecutarlas, bien para aprobar una ley o modificar la Constitución.

Este documento-síntesis-cuyo contenido proviene, sin excepción, del trabajo realizado por los nueve equipos y plasmado en sus reportes - tiene la intencionalidad de constituirse en material de trabajo, en búsqueda de consenso y compromiso en torno a las reformas a realizar y cómo lograr que sean puestas en práctica.

Quizás el aporte más importante de este trabajo -además de indicar cómo lograr las reformas, a través de las estrategias más adecuadas - es representar una oportunidad de buscar el consenso y los compromisos que permitan pasar de las propuestas a los resultados. INTEC se compromete a presentar este ejercicio de planificación estratégica para la reforma política a distintos sectores sociales, politicos y económicos, que por su representatividad y poder, son factores determinantes para que esas reformas se conviertan en realidad.

Sobre los nueve reportes elaborados por especialistas dominicanos e internacionales, queremos informar que los mismos se encuentran ya disponibles en la Biblioteca de INTEC, en un número suficiente de ejemplares, para su consulta por parte de personas e instituciones interesadas. Se contempla, también, una posterior publicación de los mismos.

Deseo concluir testimoniando nuestro agradecimiento institucional al Proyecto para el Apoyo a Iniciativas Democráticas (PID) - administrado por la Pontificia Universidad Católica Madre y Maestra 
(PUCMM) y que cuenta con el apoyo financiero de la Agencia de los Estados Unidos para el Desarrollo Internacional (USAID) - por la confianza depositada en nuestra Universidad.

Nuestro agradecimiento, también, al Centro de Asesoría y Promoción Electoral(CAPEL) - programa especializado del Instituto Interamericano de Derechos Humanos (IIDH), de San José, Costa Rica por haberse ocupado de manera tan eficientey profesional de coordinar la asesoría internacional que fue necesaria.

Finalmente, vaya nuestro aprecio y gratitud a los especialistas nacionales e internacionales que tuvieron a su cargo la elaboración de los trabajos que fueron materia prima de este ejercicio de planificación estratégica para la viabilidad de las reformas políticas.

Rafael Toribio

Rector 
LA REFORMA POLÍTICA EN LA REPÚBLICA DOMINICANA

\section{ESTRATEGIAS PARA DESARROLLAR UN SISTEMA POLÍTICO DEMOCRÁTICO, FUNCIONALY Y PARTICIPATIVO}

\section{EL POR QUÉ DE ESTE EJERCICIO DE PLANIFICACIÓN ESTRATÉGICA}

\section{Introducción}

El sistema político dominicano, integrado por el Estado, los partidos políticos y la sociedad civil, requiere de reformas que lo hagan más democrático, funcional yparticipativo. En algunos casos se necesita formular nuevas propuestas de reformas. En otros casos hay propuestas formuladas que requieren de aprobación. En otras ocasiones, las reformas se han aprobado y lo que se necesita es su implementación. Esta diversidad de situaciones y la urgencia de mejorar la funcionalidad del sistema político dominicano, motivan este proyecto de estrategias para la reforma política en la República Dominicana.

La coyuntura actual es propicia para proponer y realizar las reformas de modernización estatal y democratización política. El cambio de gobierno el 16 de agosto de 1996 y la intención expresa del presidente Leonel Fernández, mediante la creación de una Comisión Presidencial para la Reforma y Modernización del Estado, que preside el propio Presidente, sugieren la posibilidad de que se aprueben e implementen reformas políticas innovadoras que permitan avanzar hacia la creación de un sistema político más democrático, funcional y participativo.

A la intención del Presidente Fernández se unen la de los organis- 
mos internacionales de cooperación, tales como el Programa de Naciones Unidas para el Desarrollo (PNUD), el Banco Interamericano de Desarrollo (BID), el Banco Mundial, la Unión Europea y la Agencia de los Estados Unidos para el Desarrollo Internacional (USAID), así como de gobiemos amigos (España, Francia, Italia y Estados Unidos), que han expresado su disposición de colaborar con recursos técnicos y financieros en la reforma y modernización política.

Hay que destacar también las numerosas iniciativas de organizaciones e instituciones de la sociedad civil dominicana que han elaborado propuestas para la reforma política; entre ellas, el Centro Universitario de Estudios Políticos y Sociales (CUEPS) de la Pontificia Universidad Católica Madre y Maestra, el Consejo Nacional de la Empresa Privada (CONEP), la Asociación Nacional de Jóvenes Empresarios (ANJE), la Fundación Institucionalidad y Justicia (FINJUS), el Grupo de Acción por la Democracia (GAD), Participación Ciudadana, Fundación Siglo 21 y el Centro de Investigación para la Acción Femenina (CIPAF). Estas organizaciones han expresado en múltiples ocasiones su disposición de colaborar en el diseño e implementación de estrategias para la modernización del Estado, que son necesarias para promover y sostener el desarrollo económico y social de la República Dominicana.

La existencia de estas condiciones favorables hicieron pensar a los directivos del Instituto Tecnológico de Santo Domingo (INTEC) en la conveniencia de organizar un "ejercicio de planificación estratégica" para contribuir al desarrollo y la modernización del sistema político dominicano, a fin de transformarlo en uno más democrático, funcional y participativo. El propósito de este ejercicio consiste en presentar un diagnóstico de las distintas áreas del sistema político, identificar las áreas prioritarias de acción, el orden secuencial óptimo en que deben realizarse las reformas, los métodos y tácticas a utilizar en diferentes situaciones, los factores favorables, los posibles aliados, las dificultades, y los recursos materiales y humanos necesarios.

Dos características sobresalen al analizar las propuestas para la reforma política elaboradas en la República Dominicana en las últimas dos décadas. Por un lado, existe bastante coincidencia en tomo a las reformas y acciones que deben emprenderse. Es decir, se tiene bastante claro qué hacer. Sin embargo, no se ha profundizado lo suficiente en 
cómo proceder para lograr que se aprueben y ejecuten las reformas sugeridas.

Las propuestashasta ahora elaboradas son ricas en diagnósticos de situación y listados de reformas, pero la mayoría de ellas no presentan los pasos necesarios para que las reformas lleguen a aprobarse e implementarse. A saber, priorización de las reformas según su importancia y factibilidad, análisis de los factores que pueden influir favorable o desfavorablemente en la materialización de esas reformas, y el diseño de las tácticas más adecuadas para lograr su aprobación y puesta en ejecución.

\section{Objetivos del Ejercicio de Planificación Estratégica}

\section{Objetivo General}

El objetivo general de este ejercicio es, después de determinar las reformas que son necesarias realizar, identificar las acciones urgentes que deben emprenderse para que el sistema político dominicano avance hacia una democracia verdaderamente participativa y funcional.

\section{Objetivos Específicos:}

Los objetivos específicos son los siguientes:

- Identificar las principales áreas que dentro del sistema político dominicano necesitan ser reformadas.

- Realizar un diagnóstico esquematizado de la situación de cada área a ser reformada.

- Establecer un rango de prioridades entre las áreas de reforma, a fin de poder determinar el orden temporal - simultáneo o secuencial- y el grado de intensidad recomendables para las reformas o acciones concretas que se emprenderán en cada una de esas áreas.

- Ordenar, priorizar y esbozar sumariamente dentro de cada área 
de reforma, las principales modificaciones y acciones concretas consideradas necesarias o muy deseables para el desarrollo democrático del sistema político dominicano.

- Identificar los factores que pueden tener un impacto significativo sobre el éxito o fracaso de las reformas o acciones propuestas: condiciones favorables y desfavorables a las reformas, y acciones y recursos requeridos y disponibles.

Estos aspectos constituyen el núcleo central de este experimento de ingeniería política emprendido por el Instituto Tecnológico de Santo Domingo (INTEC), razón por la cual, ameritan algunas explicaciones adicionales.

Lo primero es enfatizar que los factores con impacto en las reformas y su implementación se han tenido muy en cuenta al determinar qué reformas y acciones concretas conviene adoptar, así como las tácticas a emplear para que esas reformas o acciones puedan tener éxito. Lo segundo es que la labor de priorización entre las reformas o acciones concretas seha desarrollado en el plano micro o de corto plazo y macro o de mediano/largo plazo.

Estrategia Micro o de Corto Plazo: consiste en acciones que cuentan con las siguientes características: no necesitan reformas legales ni constitucionales para su implementación; son capaces de producir resultados significativos y palpables en un corto espacio de tiempo; no desencadenan un fuerte rechazo u oposición en el plano social o político; y no suponen un costo financiero desmesurado.

Estrategia Macro o de Mediano/Largo Plazo: consiste en reformas o acciones que requieren de cambios en la legislación vigente, incluidos los cambios constitucionales, cuyo impacto es palpable en el largo plazo; reformas o acciones que pueden desencadenar conflictos importantes entre las fuerzas políticas del país; $o$ acciones que requieren de amplios recursos económicos para su ejecución.

Estrategia Alternativa: cuando se evalúa que una reforma importante no es viable por lo menos en el corto plazo, se propone una "estrategia alternativa". En todas las estrategias propuestas se esboza 
en alguna medida cómo hay que actuar para que las reformas o acciones recomendadas puedan tener éxito. El esfuerzo por esbozar las tácticas a emplear se hace a la huz del escenario político vigente en la República Dominicana.

Entre los factores que han tenido un impacto significativo en el propuesto proceso de reforma se incluyen siempre que sea posible:

- Los posibles aliados y fuentes de oposición a la reforma; es decir, personas o instituciones que pudiesen apoyar $u$ oponerse a las reformas que se vayan a emprender.

- Las ventajas coyunturales que podrían favorecer las acciones de reformas, así como los obstáculos de diverso orden que se podrían presentar en el camino de la reforma propuesta.

- Los recursos humanos y financieros requeridos para las reformas 0 acciones seleccionadas.

- La agregación de demandas a favor de dichas reformas o acciones. Se trata, en otras palabras, de tener muy en cuenta el papel estelar que en todo proceso de reforma política juega la sociedad civil organizada en coaliciones de amplia base.

\section{$\underline{\text { Areas Prioritarias }}$}

Las áreas escogidas como prioritarias en este ejercicio de planificación estratégica de la reforma política incluyen: la modernización del Estado, del sistema electoral, de los partidos políticos, reformas a la constitución, la sociedad civil y los medios de comunicación. Por esta razón los análisis y propuestas específicas de reforma y fortalecimiento institucional se realizaron en las siguientes nueve áreas:

- Constitución

- Sistema Electoral

- Partidos Políticos

- Poder Judicial

- Poder Legislativo 
- Municipio y Poder Local

- Administración Pública y Servicio Civil

- Sociedad Civil

- Medios de Comunicación

\section{Metodología Empleada}

Para el análisis de cada área y la producción del documento final por temática, se contó con una guía metodológica común a todos los equipos de trabajo. Entre las principales actividades realizadas por los equipos en base a la guía indicada, se incluyen las siguientes:

- Recopilación y análisis de los principales documentos de diagnóstico y propuestas de reforma en torno al sistema político dominicano elaborados en los últimos años.

- Reuniones para la "lluvia de ideas" en torno a las reformas convenientes y deseadas. Esta metodología fue utilizada tanto en sesiones plenarias de los equipos de trabajo como en las reuniones de los equipos por área.

- Se utilizó la metodología de análisis conocida como "mapeo político" e "identificación y análisis de los grupos de interés involucrados". Sobre estastécnicas metodológicas se realizó un taller conducido por el Dr. Benjamin Crosby, analista político de los Estados Unidos, y se distribuyó documentación escrita sobre el tema a los equipos de trabajo.

- Los informes por área fueron ajustados a un formato común que incluía los siguientes elementos: análisis del estado de situación del área, análisis de los factores favorables y desfavorables a la reforma, reformas propuestas en el corto, mediano y largo plazo, o reformas y estrategias alternativas.

- Cada documento por área temática contiene al final un cuadro esquemático del plan de reforma propuesto

- Los equipos de trabajo por área realizaron reuniones conjuntas 
antes de iniciar sus labores especializadas, así como, durante el proceso de preparación de los informes. Los miembros de los equipos nacionales se reunieron con expertos internacionales que visitaron la República Domimicana para asesorar los equipos de trabajo en las diversas áreas temáticas.

- Al concluir los primeros borradores de informes por área, el INTEC convocó a una reunión con representantes de la sociedad civil, lospartidos políticos y los poderes del Estado para escuchar sus opinionesy sugerencias en tomo a los documentos preparados. Estas sugerencias fueron tomadas en consideración en la redacción final de los documentos por área.

\section{Equipo Profesional a Cargo del Proyecto}

La elaboración del análisis por áreas, que abarcó los meses de septiembre a noviembre de 1996, fue encomendada por el INTEC a un grupo de 27 expertos dominicanos y ocho internacionales. Todos fueron seleccionados por ser especialistas con amplia experiencia y reconocida trayectoria en distintas áreas de la reforma política. Los expertos intemacionales, a su vez, poseían previo conocimiento del sistema político dominicano.

Para colaborar en la selección de los expertos internacionales, y responsabilizarse de los trámites necesarios para su contratación y viajes de consultoría a la República Dominicana, el INTEC solicitó la asesoría y colaboración del Centro de Asesoría y Promoción Electoral (CAPEL), programa especializado del Instituto Interamericano de Derechos Humanos (IIDH), con sede en San José, Costa Rica. La designación del IIDH/CAPEL fue hecha por el INTEC atendiendo al reconocimiento y la vasta experiencia de esta institución latinoamericana en el área de democracia y gobernabilidad, así como, a su conocimiento directo de la actual coyuntura política que vive la República Dominicana.

En septiembre de 1996, el INTEC solicitó financiamiento para ejecutar el "ejercicio de planificación estratégica" al Programa de Apoyo de Iniciativas Democráticas (PID). EI PID es administrado por la Pontificia Universidad Católica Madre y Maestra (PUCMM) con 
fondos suministrados por la Agencia de los Estados Unidos para el Desarrollo Internacional (USAID). El 18 de septiembre, el Consejo Consultivo del PID aprobó con entusiasmo el proyecto.

El grupo que diseñó el "ejercicio de planificación estratégica", procedió en agosto de 1996 a seleccionar las áreas prioritarias que dentro del sistema político dominicano necesitaban reforma: Estado, partidospolíticosy sociedad civil Las áreas prioritarias se determinaron en la fase inicial del proyecto, porque de esa selección dependía el tipo de especialista que debería escogerse. Los especialistas nacionales e internacionales escogidos formaron equipos para la preparación de documentos por área temática.

Constitución: Eduardo García Michel (coordinador), Flavio Darío Espinal y Eduardo Jorge Prats. Daniel Sabsay (especialista internacional, Argentina).

Sistema Electoral: José del Castillo (coordinador), Pedro Catrain y Adriano Miguel Tejada. Daniel Sabsay (especialista internacional, Argentina).

Partidos Políticos: EmmanuelCastillo(coordinador), Laura Faxas y José Oviedo. Enrique Baloyra (especialista internacional, Cuba/ Estados Unidos.) y Rosario Espinal (especialista internacional, República Dominicana/Estados Unidos).

Poder Judicial: Yolanda Martínez (coordinadora), Milton Ray Guevara, y Wellington Ramos Messina. Alvaro Ferrandino (especialista internacional, Costa Rica).

Poder Legislativo: Sonia Díaz (coordinadora), Vinicio Tobal y José del Castillo. Constantino Urcuyo (especialista internacional, Costa Rica).

Municipioy Poder Local: JorgeCela (coordinador), Fran Cáceres y Pedro Hernández. Manuel Rachadell (especialista internacional, Venezuela).

Administración Pública y Servicio Civil: Luis Scheker Ortiz (coordinador), Raymundo Amaro y Teobaldo Rodríguez. 
Sociedad Civil: Marco Villamán (coordinador), José Ceballos y Adalberto Martínez EnriqueBaloyra (especialista internacional, Cuba/ Estados Unidos) y Rosario Espinal (especialista internacional, República Dominicana/Estados Unidos).

Medios de Comunicación: Juan Bolívar Díaz (coordinador), Manuel Quiterio Cedeño y Fausto Rosario Adames. José Antonio Mayobre, hijo (especialista internacional, Venezuela).

Estosnueve equipos de trabajo fueron coordinadospor el Director Ejecutivo del proyecto, Carlos Dore Cabral. Fungió como Oficial de Enlace del IIDH/CAPEL, Ricardo Valverde. En la elaboración del presente documento colaboraron José del Castillo, Emmanuel Castillo y Carlos Dore. La redacción final del mismo estuvo a cargo de Rosario Espinal. 


\section{LA REFORMA POLÍTICA EN AMÉRICA LATINA}

La preocupación por la consolidación democrática y la gobernabilidad seha convertido en un asunto central en América Latina. Cuando se inició la transición de los regímenes autoritarios a la democracia, a finales de los años 70 y durante los 80 , el tema que ocupó la atención fue la explicación del por qué y cómo se habían realizado dichas transiciones. La crisis económica de los años 80 agudizó la preocupación por la fragilidad delnuevo orden democrático, en particular, por su correlación con la conflictividad social y política. Este fue un periodo de políticas de fuertes ajustes estructurales auspiciadas por el Fondo Monetario Internacional (FMI), que perseguían estabilizar las economías sobrecargadas por el peso de la deuda, déficits fiscales, hiperinflación, devaluación y crisis del sector externo.

Estas políticas económicas se acompañaron de una fuerte movilización social y de transformaciones importantes en la naturaleza de los actores políticos y en las características del Estado latinoamericano. Partidos políticos de tradición populista como el Partido Revolucionario Institucional (PRI) de México, o el Partido Peronista en Argentina, cambiaron su estrategia de gobierno, el discurso político y las tradicionales alianzas de clase con los sectores trabajadores. Paralelamente, en muchos paises de América Latina los gobiernos democráticos fracasaban en su gestión gubernativa, al no dar respuesta a las demandas emergentes de la sociedad y agotar su legitimidad política rápidamente como resultado de la corrupción en el sector público.

A finales de los años 80 se hizo evidente que los sistemas políticos latinoamericanos requerían de reformas importantes para poder dar respuesta a las nuevas demandas de la economía internacional, a las expectativas delapoblación, y mantener asíuna legitimidad democrática 
con eficiencia en la administración pública. En otras palabras, el nuevo contexto de globalización económica que vive la región, unido al propósito de preservar la democracia, evidenció la necesidad de perfeccionar las instituciones políticas para hacerlas realmente funcionales y participativas.

Las experiencias de reforma política en América Latina son diversas y han ocurrido en momentos distintos. Sin embargo, las intenciones y las áreas específicas de reforma muestran similaridad. En diversos países se han realizado reformas constitucionales con el objetivo de incorporar nuevos actores políticos y asegurar su representación en las estructuras gubernamentales. Son también evidentes los esfuerzos por mejorar la funcionalidad del sistema judicial y legislativo, combatir la corrupción en la administración pública y perfeccionar los sistemas electorales.

Garantizar la gobernabilidad democrática ha constituido una razón sustancial para promover las reformas políticas. Junto a las denominadas reformas estructurales de la economía se ha propuesto, a veces conjuntamente o con posterioridad, una reforma del Estado. Sus líneas principales se han orientado a:

- Rediseñar el Poder Ejecutivo para hacer su ejercicio más colegiado, mediante la delegación de mayores potestades a los Ministros, profesionalización de la burocracia, reordenamiento de las agencias gubernamentales superpuestas y transferencia de potestades, servicios y recursos mediante leyes y planes de descentralización del gobierno.

- Remodelar el sistema de representación, mediante el establecimiento, en algunos casos, de la elección de cargos que antes eran designados por el Ejecutivo, como los gobernadores; la creación de órganos de participación de los representantes de la sociedad civil a nivel regional y local, en los que concurren las autoridades electivas; así como, la adopción en algunos países del sistema unicameral.

- En el ámbito electoral se han depurado los padrones electorales y modemizado el sistema de identificación; se han fortalecido las instituciones electorales y actualizado las leyes; se han separado los niveles de elección (presidencial, congresional, local); se han incorporado nuevas figuras, como las consultas populares para dirimir asuntos 
controversiales(referéndum, plebiscito); seha implementado una legislación sobre partidos políticos como parte de los códigos electorales o como leyes independientes; y se ha establecido el sistema de elecciones primarias, que se ha ido abriendo paso en la región para seleccionar candidatos dentro de los partidos políticos.

- Otro asunto fundamental ha sido la reforma y modernización del sistema judicial, mediante el establecimiento de la carrera judicial, una mayor independencia presupuestaria y administrativa de los tribunales, el establecimiento de un órgano concurrente de los tres poderes del Estado para la selección de los jueces; la creación en algunos países de la figura del Defensor del Pueblo o Procurador de los Derechos Humanos (Ombusman); la actualización de las leyes y la promoción de campañas de educación ciudadana en materia de derechos humanos y civiles.

- Un componente importante de la reforma ha sido el fortalecimiento de los órganos de control del Estado y de los mecanismos de interpelación congresional de los funcionarios electivos. La lucha contra la comupción ha costado la presidencia a Jefes de Estado en Brasil y Venezuela, y en marzo de 1996 se suscribió en Caracas la Convención Latinoamericana contra la Comupción, en una Asamblea convocada por la Organización de los Estados Americanos (OEA).

- En casi todos los países latinoamericanos la Constitución ha sido modificada, parcial o integralmente, por el poder legislativo o mediante convocatorias a asambleas constituyentes.

- En la reforma de América Latina la descentralización ha sido un tema de gran importancia y significación. El fortalecimiento del poder local no es algo nuevo por cuanto pertenece a la tradición americana representada en el cabildo. En cierto sentido la descentralización viene a representar la devolución de un poder que la comunidad ejercía en el cabildo.

Modernamente viene a representar la participación de la Comunidad en el manejo de los asuntos locales, donde la experiencia de Bolivia, con la Ley de Participación Popular, es el ejemplo más reciente. 
El impacto concreto de estas reformas políticas en América Latina está aún por evaluarse. Lo que sí puede afirmarse es que estas reformas se han realizado en un contexto de demanda de democratización del sistema político, en función del balance de fuerzas entre los distintos actores políticos, y en el contexto del marco político-institucional existente en cada país. 


\section{LA REFORMA POLÍTICA EN LA REPÚBLICA DOMINICANA}

\section{Estado de Situación}

La reforma del Estado ha sido identificada por los partidos políti$\cos$, los grupos organizados de la sociedad, entidades académicas, organismos internacionales y por la administración del Presidente Leonel Fernández, como un objetivo de carácter esencial a los fines de hacer de este ente y de sus funciones un instrumento más eficaz al servicio del desarrollo, la equidad y la democratización real de la sociedad dominicana y sus instituciones. La propia viabilidad del sistema político, en el contexto de una economía mundial cada vez más dependiente y una comunidad internacional más protagónica, exige la modernización y democratización de las instituciones gubernamentales, con el propósito de hacerlas más representativas, participativas y funcionales, susceptibles de auditoría por parte de la ciudadanía.

Aunque en los últimos 20 años el país ha logrado indudables progresos en la estabilización de sus instituciones democráticas, dirigidos a generar un clima de convivencia ciudadana y a reivindicar el diálogo y la concertación para la resolución de los conflictos entre sus actores sociales y políticos, el funcionamiento del sistema político sigue adoleciendo de numerosas fallas.

Un apretado diagnóstico del sistema político dominicano evidencia su alto componente presidencialista, con fuerte centralización de las decisiones en el Ejecutivo y un claro desbalance entre los poderes 
delEstado, determinadoporun Congreso relativamente débil - aunque en creciente incremento de su influencia - y un Poder Judicial carente de autonomía real y profesionalización. Los gobiernos municipales muestran un alto nivel de inoperatividad debido a la falta de recursos y facultades políticas, atrapados en viejos modelos de gestión administrativa que han sido superados por las nuevas realidades urbanas.

La ausencia de políticas estatales que den continuidad a la gestión pública, así como, la personalización de la controversia política, han limitado significativamente la eficacia de las instituciones gubernamentales. Los efectos nocivos del clientelismo político, el caudillismo y la preservación de los valores y prácticas autoritarias, han frenado la necesaria modernización de las instituciones democráticas, incluyendo los partidosmayoritarios, cuyos procesos de democratización interna han sido frecuentemente mediatizados por la pervivencia de estos rasgos de la cultura política domimicana. La escasa vinculación entre la dinámica de los partidos y las agendas de reformas gestadas por las organizaciones de la sociedad civil, marca un divorcio entre actores que deben ser complementarios en el funcionamiento del sistema democrático, a pesar de la inclusión formal de dichas agendas en los programas de gobiemo de los partidos.

El modelo presidencialista dominicano es uno de los más extensos de su género en América Latina por su peso en el sistema político, derivado tanto del ordenamiento constitucional, como de la práctica gubeinamental en el manejo de la administración pública, la ejecución presupuestaria, y su función arbitral en la sociedad.

El artículo 55 de la Constitución otorga poderes ilimitados al Presidente, complementado por el artículo 41 , que prácticamente anula el poder Legislativo, al exigir al Congreso una mayoría calificada de las dos terceras partes de la matrícula de cada cámara para contrarrestar la observación de una ley por parte del Ejecutivo.

Un código no escrito - fueltemente afincado en la cultura política dominicana - potencia aún más el rol del Presidente de la República en el sistema político. La Encuesta Demos 94 reveló que el Presidente es la jerarquía del Estado que alcanza el mayor porcentaje (33\%) de "mucha confianza" depositada por la población, por encima de cualquier otra entidad de la sociedad política. En adición, el $45 \%$ identificó 
al entonces incumbente de dicha función, Joaquín Balaguer, como "el líder que más había contribuido al desarrollo de la democracia en el país". Balaguer encabezó la jefatura del Estado durante 22 de los últimos 30 años, cubriendo seis de los ocho períodos constitucionales desde 1966 hasta 1996.

\section{La Constitución}

Las principales reformas políticas introducidas en años recientes al Poder Ejecutivo tienen que ver con las enmiendas constitucionales de 1994, que prohiben la reelección presidencial, establecen la elección del Presidente y el Vicepresidente mediante el sistema de mayoría absoluta a doble vuelta, y separan las elecciones presidenciales de las congresionales y municipales.

La reforma constitucional de 1994 tuvo como principal motivación la búsqueda de una salida a la crisis postelectoral. Se enfatizó en la necesidad de modificar el sistema de elección a cargos públicos - la prohibición de la reelección presidencial, la doble vuelta, $(50+1)$ y elecciones separadas - y se agregaron otras medidas destinadas a fortalecer la autonomía del Poder Judicial y reconocer derechos de ciudadanía a los dominicanos que habían obtenido otra nacionalidad (la doble ciudadanía).

Por su carácter parcial y condicionado a la solución rápida de la crisis electoral de 1994, y por la concentración de la toma de decisiones en las cúpulas partidarias, la reforma constitucional de 1994 dejó pendientes múltiples asuntos que han estado siendo debatidos sobre el Poder Ejecutivo, el Congreso, el Poder Judicial, los Ayuntamientos, el Sistema Electoral, la Contraloría, los nuevos derechos de ciudadanía, y la participación de la sociedad civil en los procesos de reforma constitucional.

La necesidad de una nueva reforma política ha tomado vigencia a partir de 1994. Unosproponen una revisión constitucional por la actual legislatura, otros favorecen la convocatoria a una Asamblea Constituyente en 1998, y algunos favorecen una reforma constitucional por parte del nuevo Congreso que surja electo en'1998. Estas alternativas abren caminos y posibilidades diferentes. 
Existe el temor de que una revisión por parte de la actual Asamblea Nacional se oriente hacia una reforma parcial del texto constitucional, determinada por la capacidad de pactar del Partido Reformista Social Cristiano (PRSC) y el Partido Revolucionario Dominicano (PRD), quienes tienen la mayoría necesaria para proceder a modificar la Constitución. El Partido de la Liberación Dominicana (PLD) y el Presidente de la República, Leonel Fernández, así como sectores organizados de la sociedad civil, se han opuesto a un proceso de revisión constitucional por la actual Asamblea.

Los que propician reformas integrales al texto constitucional y una mayor representatividad de la sociedad dominicana prefieren una Asamblea Constituyente que se elija en el contexto de las elecciones congresionales y municipales de 1998. Una Asamblea Constituyente elegida popularmente y con representación de los partidos políticos, sectores sociales organizados y personalidades independientes, podría garantizar una mayor representatividad, una mejor preparación técnica, y la posibilidad de estructurar un nuevo pacto constitucional de amplio espectro legitimador y mayor durabilidad en el tiempo.

La convocatoria a una Asamblea Constituyente requiere, sin embargo, de modificaciones a los artículos de la Constitución que se refieren a las reformas constitucionales (artículos del 116 al 120), y la aprobación de una legislación que establezca la composición de la Asamblea, su forma y fecha de elección, el período de duración de sus trabajos y la organización de los mismos, entre otros aspectos.

\section{EI Sistema Electoral}

En 1992 se hizo una reforma a la Ley Electoral mediante la cual se creó la Dirección General de Elecciones y la Administrativa; se amplió de tres a cinco el número de miembros de la Junta Central Electoral (JCE); se le traspasó a la JCE la Dirección General de la Cédula de Identidad Personal y la Oficina Central del Estado Civil; se delimitaron las funciones administrativa, reglamentaria y jurisdiccional; se separaron los tres niveles de elección nacional, congresional y municipal; y se encomendó reglamentar las alianzas, la democracia interna de los partidos, las actividades de campaña, la publicidad electoral, el acceso a los medios de comunicación, la publicación de encuestasyla observación técnica de lospartidosen el Centro de Cómputos. 
Esta reforma definió mejor los plazos relativos a determinadas fases del proceso electoral, tales como, formalización de las alianzas, inscripción de las candidaturas y entrega del listado de electores a los partidos.

Del mismo modo, en esa ocasión se ordenó la renovación del padrón electoral y la unificación del sistema de identificación ciudadana con el del Registro Electoral. Este proceso pasó por fases sumamente críticas, llegando a su climax en 1994, con la dislocación de electores en un número significativo de Mesas Electorales y el cuestionamiento de los resultados de los comicios.

En 1995, la Ley Electoral fue enmendada de nuevo a fin de ajustarla a la reforma constitucional de 1994, que incorporó la modalidad de votación en Colegios Electorales cerrados y el sistema de doble vuelta para la elección presidencial al modificarse el régimen de mayoría relativa por uno de mayoría absoluta. Igualmente, se redujeron los plazos que regían en una serie de procedimientos, con el propósito de hacer viable la segunda elección en un plazo de 45 días, en caso de que ninguno de los candidatos obtuviera la mayoría absoluta.

Esta reforma dejó pendientes importantes aspectos, entre ellos, algunas incongruencias de la propia Ley Electoral, al quedar establecidos distintos sistemas de mayoría, uno para la elección del presidente y vicepresidente (mayoría absoluta a doble vuelta), otro para elegir senadores y síndicos (mayoría relativa), y un tercero para la elección de diputadosy regidores(sistema proporcional), sin loscorrespondientes ajustes en el texto.

Por su parte, la JCE, después de concluidas las elecciones de 1996, sometió a las cámaras legislativas un proyecto de reforma a la Ley Electoral, que contempla la creación de los distritos electorales para la elección de diputados y regidores, el financiamiento público de los partidos políticos, el establecimiento de una cuota del $30 \%$ de participación de las mujeres en los cargos electivos y el reconocimiento del derecho al voto a los dominicanos residentes en el exterior, entre otras medidas.

Los aspectos contenidos en la propuesta de reforma de la JCE, asi como, la evaluación de la experiencia electoral de 1996 en cuanto al 
funcionamiento de los Colegios Electorales cerrados, el acceso equitativo de los partidos a los medios de comunicación estatal, el desarrollo de la campaña electoral y el papel de la observación electoral por parte de entidades de la sociedad civil y de organismos internacionales, se hallan pendientes de debate por parte de los partidos, los legisladores, la JCE, y las organizaciones de apoyo del proceso electoral. Otro tema fundamental a determinar, es el grado de depuración a que se ha llegado en el padrón electoral.

Por otra parte, la propuesta de creación de los distritos electorales en el proyecto de la JCE, requiere de la realización de estudios técnicos de factibilidad, tanto en las grandes y medianas provincias, como en elDistrito Nacional. Se requiere, además, dela formulación de propuestas concretas de subdivisión, tomando en cuenta factores demográfi$\cos$, divisiones político-administrativas, demarcaciones barriales, sentido de pertenencia o afmidad de las comunidades a ser integradas o subdivididas, así como, el tamaño de cada distrito (en cuanto al número de representantes generados). Esto significa identificar las características políticas y electorales del país.

\section{Partidos Políticos}

Los partidos dominicanos han sido caracterizados como organizaciones permeadas por los rasgos predominantes del sistema político, entre los que destacan, el liderazgo caudillista y autoritario, el clientelismo y el patrimonialismo en los patrones de reclutamiento, el imperio del personalismo y el grupismo en las relaciones intrapartidarias y los nexos entre los partidos, así como la carencia de reglas institucionales claras que garanticen su funcionamiento orgánico. En su vida interna, escasamente supervisada por la JCE, se perpetúan los cuadros directivos, sin que se observen las propias regulaciones estatutarias que fijan la renovación periódica de las autoridades partidarias mediante mecanismos democráticos.

A diferencia del necesario diálogo constructivo que debe operar en una democracia funcional entre partido oficial y partidos de oposición, y de las negociaciones y los pactos, en el sistema de partidos dominicanos se impuso la pauta de exclusión y la obstrucción de la comunicación a nivel del liderazgo. Por otro lado, las agendas de los partidos corrieron paralelamente a las elaboradas por las organizaciones de la sociedad civil. 
El desarrollo de experiencias de concentración entre los actores sociales y el Estado ha reorientado, sin embargo, el comportamiento de los partidos. Fruto de ello fueron las reformas a la Ley Electoral de 1992 y el Pacto por la Democracia de 1994, que dio origen a la reforma constitucional de ese mismo año.

La otra dimensión de esta experiencia fue la sintonía alcanzada, a raíz de las elecciones de 1996, entre la agenda nacional elaborada por la sociedad civil y los programas de gobierno de los partidos. Pero la democratización de las prácticas partidarias no es homogénea. Mientras las reglas para la obtención de una candidatura han ido evolucionando, la renovación de los cuadros directivos ha permanecido estancada en losprincipalespartidos, subsistiendo viejas élitesy rutinizándose las prácticas de designación y cooptación para la selección de dirigentes.

En cuanto a la Ley de Partidos, su objetivo consiste en formular una normativa que garantice la institucionalización de estas entidades de derecho privado que juegan un papel singular y estratégico de interés público en el sistema político democrático. Son los partidos políticos, junto a las denominadas agupaciones políticas accidentales, las únicas calificadas por la Ley Electoral para nominar candidaturas a los diferentes cargos de elección directa de los poderes del Estado.

Sobre el particular hay dos caminos de reforma posibles. Uno sería aprobar una legislación especial sobre los partidos políticos, que amplíe los alcances que ya existen en la Ley Electoral sobre formación, reconocimiento y mantenimiento de la personería jurídica, incorporando una normativa detallada sobre el régimen interno y las modalidades de funcionamiento. El otro sería - como ha sucedido en algunos países de América Latina - ampliar estos aspectos en la propia Ley Electoral, entendida como una especie de Código Electoral.

Un tema importante a mencionar es el nivel de calificación de los cuadros máximos y medios de los partidos para manejar la diversidad de materias involucradas en las agendas económica, social, política, judicial, e internacional. Resulta sintomático que el grueso de las propuestas y estudios técnicos sobre estos temas ha surgido de las organizaciones de la sociedad civil y de los organismos internacionales, a las cuales los partidos se han incorporado tardíamente. 
En consecuencia, la evaluación del estado de situación en materia de legislación partidaria se halla en una fase bastante cruda, tanto en lo relativo a la formulación de propuestas específicas y coherentes, como en lo que se refiere a su discusión por los partidos, los legisladores, la Junta Central Electoral y la sociedad civil.

\section{Poder Judicial}

El Poder Judicial es uno de los pilares del Estado de derecho en los sistemas democráticos. Su débil funcionamiento ha motivado la mayor demanda de reformas orientadas a dotarlo de autonomía real, tanto en lo político, como en lo administrativo y presupuestario.

La reforma constitucional de 1994 creó el Consejo Nacional de la Magistratura (Art.64), con el objetivo de trasladar la selección de los jueces de la Suprema Corte de Justicia del ámbito del Senado al de un organismo convergente con representación del poder ejecutivo, el legislativo y el judicial, cuya composición busca un mayor equilibrio institucional y político. En adición, la facultad de designar los demás jueces-que antes correspondía al Senado- le fue conferida a la Suprema Corte de Justicia (inciso 4 del Art.67), con el propósito de sustraer dichos nombramientos de consideraciones de naturaleza extrajudicial.

El Art 63 consagra la autonomía administrativa y presupuestaria del Poder Judicial, ordena la institucionalización de la carrera judicial y declara inamovibles a los magistrados. Con ello se persigue profesionalizar la administración de justicia, estabilizar el desempeño del rol de los jueces, y estimular el desarrollo de la carrera judicial, con el objetivo de modemizar el aparato judicial y robustecer la credibilidad $y$ eficiencia de sus mecanismos operativos.

Pese a la reforma constitucional de 1994, el Poder Judicial no ha podido alcanzar un mínimo nivel de desarrollo institucional y funcional, imposibilitando con ello el establecimiento en la administración de justicia del esquema de separación e independencia de los poderes delEstado quela democracia preconiza. Elpeso delEjecutivo - atenuado en lo formal por las nuevas disposiciones constitucionales - mantiene en un estado de subordinación administrativa al Poder Judicial. La Procuraduría General de la República no sólo asume la acción pública, sino que funge también como Secretaría de Justicia y admi- 
nistra el sistema penitenciario. Por otro lado, existen en el Senado iniciativas orientadas a devolver a este órgano un mayor protagonismo en la selección de los jueces, como lo consigna el proyecto de reforma constitucional suscrito por los senadores reformistas y algunos perredeístas en 1996.

Se observan, sin embargo, signos positivos que apuntalan la reforma judicial. Tras dos años de estancamiento en la formación del Consejo Nacional de la Magistratura - pieza clave en la reforma del sistema-dicho organismoha quedado conformado, iniciando sustrabajos con la adopción de un reglamento interno. Paralelamente, el Poder Ejecutivo designó un Secretario de Estado sin Cartera a cargo de esta tarea, creándose un Comisionado para la Reforma y Modernización de la Justicia que integra a miembros del Consejo Nacional de la Magistratura, el Poder Legislativo, y representantes de la sociedad civil.

La sociedad civil por su parte, ha evidenciado liderazgo e interés en la modernización del aparato judicial. Entidades como la Fundación Institucionalidad y Justicia (FINJUS), los gremios de abogados, el Consejo Nacional de la Empresa Privada(CONEP), la Iglesia Católica, las universidades, y el Grupo de Acción por la Democracia (GAD), entre otros, han identificado esta reforma como prioritaria para la institucionalización del Estado y la creación de un verdadero estado de derecho. Organismos internacionales, como la USAID, el BID, y el PNUD, y gobiemos amigos de la República Dominicana han formalizado o expresado su interés de colaborar con esta tarea.

\section{Poder Legislativo}

El funcionamiento del Poder Legislativo se encuentra afectado por problemas de orden estructural, de naturaleza constitucional, legal y reglamentaria, por deficiencias funcionales y administrativas, y por patrones de comportamiento legislativo que se corresponden con las prácticas políticas tradicionales.

El sistema bicameral establecido en la Constitución se caracteriza por una marcada asimetría en la distribución de facultades entre ambas cámaras que concede mayores facultades al Senado -la cámara menos plural en su composición política, social y territorial, y la más desproporcionada en su representación electoral. 
El Senado registra una representación desproporcionada, tanto de los electores como de los partidos, en virtud de los efectos políticos del sistema de mayoría relativa aplicado a circunscripciones uninominales que exhiben dramáticas diferencias en el tamaño de su población, con una división en 29 provincias y un distrito nacional En el Distrito Nacional de Santo Domingo resideel $30 \%$ de loselectoresy en Santiago (la mayor de las provincias) el $10 \%$. Estos electores experimentan un grave déficit de representación y, en menor medida, los de las provincias medianas (seis provincias que tienen entre el $6 \%$ y el $3 \%$ de los electores), en tanto que los electores de las pequeñas provincias(nueve de ellas tienen entre $2 \%$ y $3 \%$, y trece están por debajo del $2 \%$ ) cuentan con una sobrerepresentación, ya que eligen la mayoría de los escaños.

En la Cámara de Diputados, en cambio, el problema es la carencia de relación vimculante entre los diputados y sus electores en las grandes demarcaciones que, como en el Distrito Nacional de Santo Domingo, eligen 31 diputados, pero de acuerdo con los datos censales de 1993 debieron elegir 42 en 1994. Para ese tipo de demarcación seha planteado la creación de distritos electorales.

El poder del Presidente de la República ha gravitado tradicionalmente en la dinámica del Congreso - incluida la selección de los bufetes directivos- - al coincidir en su figura el liderazgo del partido que controla la mayoría congresional o la de una de sus cámaras y disponer de los recursos necesarios para recompensar el favor de los legisladores. La carencia de autonomía administrativa y presupuestaria del Congreso ha reforzado esta tendencia. Sin embargo, en los últimos tiempos se observa una clara tendencia hacia la "autonomía" de los legisladores, quieneshan reivindicado su poder específico en el sistema político, tanto frente al Ejecutivo, como ante los grupos de presión y frente a las propias directrices de sus partidos.

El hecho de que el Partido de la Liberación Dominicana (PLD) sólo cuenta con 12 diputados (de 120) y 1 senador (de 30), ha inaugurado una nueva etapa en las relaciones Congreso-Ejecutivo, caracterizada por frecuentes encuentros de trabajo entre el Presidente y los líderes congresionales para debatir la agenda legislativa. Un antiguo legislador del PLD actúa de enlace entre ambos poderes, con rango de Secretario de Estado sin Cartera. 
En legislaturas recientes, y en la presente, los desacuerdospolíticos y las presiones de los grupos de interés han dilatado la aprobación de proyectos de leyes de capital importancia para las reformas estructurales de la economía y de las instituciones sociales. La propia dinámica de aprobación de las leyes por parte de ambas cámaras y la frecuente "caída" de los proyectos al perimir una legislatura, indican la necesidad de revisar este mecanismo.

Entre los factores que limitan la labor del Congreso se observan, la vigencia de reglamentos internos obsoletos y tecnología no actualizada, la falta de recursos de apoyo (administrativos y técnicos) al trabajo legislativo, la existencia de una planta fisica limitada para el funcionamiento de las comisiones y los bloques parlamentarios, la carencia de oficinas congresionales en las provincias que faciliten el contacto entre legisladores y electores, y la falta de autonomía presupuestaria.

La solución de algunos de estos problemas requiere de reformas constitucionales o legales (como la reformulación de las facultades de las cámaras, modificaciones en el sistema de representación y la creación de los distritos electorales), a cuyos fines existen propuestas como las discutidas por los partidos políticos en los talleres de 1994 organizados por la Fundación Siglo 21 y el proyecto de reforma a la Ley Electoral sometido por la JCE al Congreso. Para la modemización del Congreso existe un convenio con el BID y entre los objetivos de la Comisión para la Reforma y Modemización del Estado se incluye el Poder Legislativo, para lo cual se contaría con el apoyo del PNUD.

\section{Municipio y Poder Local}

Los problemas que aquejan la organización municipal son de orden constitucional, electoral, legal, técnico y administrativo. Los mismos pueden enunciarse como sigue: el limitado alcance constitucional del régimen municipal y la existencia de leyes que desvirtúan la autonomía de los ayuntamientos; la no actualización de la propia legislación municipal; la existencia de estructuras administrativas ineficaces que, debido a su diseño original para municipios con perfiles demográficos, económicos e institucionales dispares, resultan desbordadas por la dinámica del desarrollo urbano y rural; la escasez de recursos presupuestarios que resulta en un elevado nivel de dependen- 
cia de las decisiones y los subsidios del Gobiemo Central; la carencia de potestades reales para imponer normas, regulaciones y arbitrios, lo cual limita su capacidad de prestación de servicios; la escasa relación entrelosmunícipes y susrepresentantes, particularmente en las grandes ciudades, debido al modelo de organización electoral imperante y a la propia estructura del gobierno municipal; la fatta de coordinación entre los ayumtamientos y las organizaciones de base y organizaciones no gubernamentales (ONG's); la limitada participación ciudadana en el proceso de toma de decisiones.

A lo anterior se suman otros problemas de índole técnico-administrativo: el bajo nivel de profesionalización de las autoridades municipales y el personal administrativo; la falta de motivación creada por la ausencia de incentivos salariales y la inestabilidad en el cargo; la existencia de criterios clientelistas en el reclutamiento del personal; la escasa capacidad técnica para planificar y supervisar el desarrollo urbano; la falta de coordinación entre municipios conexos y la Liga Municipal Dominicana

La celebración simultánea de elecciones municipales, presidenciales y congresionales que caracterizó el sistema electoral dominicano en el pasado, relegó a un segundo plano el debate de la temática local. Al separar las elecciones presidenciales de las congresionales y municipales, la reforma constitutional de 1994 podría resolver esta dificultad si a las elecciones locales se les atribuye la importancia que tienen y si se hacen las modificaciones necesarias para conceder recursos y capacidad decisoria a los municipios.

Existen propuestas de reforma elaboradas por foros municipales auspiciados porla Fundación Siglo 21, la Pontificia Universidad Católica Madre y Maestra (PUCMM), el Grupo de Acción por la Democracia (GAD), y el Congreso de Municipios celebrado en junio de 1995 con el auspicio de la Liga Municipal Dominicana. A su vez, el PNUD, mediante la firma de un convenio con el Secretariado Técnico de la Presidencia y la Liga Municipal Dominicana, respalda un proyecto para la descentralización y el fortalecimiento de los gobiemos locales. Entre tanto, la Oficina Nacional de Planificación (ONAPLAN) ha anunciado la formación de Consejos Provinciales de Desarrollo, integrados por representantes del gobierno y de las organizaciones cívi- 
cas municipales que integran cada provincia. Dichos Consejos tendrían como objetivo implementar los programas de desarrollo social y servir de canales de participación en la gestión local. Por su parte, la JCE ha planteado en su proyecto de reforma a la Ley Electoral la creación de distritos electorales a nivel municipal para la elección de los regidores.

\section{Administración Pública y Servicio Civil}

El diagnóstico de la administración pública dominicana muestra la existencia de un alto nivel de centralización, que resulta en una superposición de organismos y funciones con escasos mecanismos de planificación y control, lo que la convierte en desordenada e ineficaz. Estos rasgos determinan, a su vez, la ausencia de normas y procedimientosmodernos que promuevan una política de selección de personal basada en la profesionalización y una remuneración adecuada. Por otra parte, la falta de una disposición de servicio, la informalidad y la indisciplina revelan la inexistencia de una verdadera cultura administrativa.

La principal reforma al Poder Ejecutivo en su función administrativa tiene que ver con la promulgación de la Ley de Servicio Civil y Carrera Administrativa de 1991, destinada a profesionalizar de manera progresiva la administración pública. El reglamento de aplicación de dicha Ley fue aprobado en 1994. La Oficina Nacional de Personal (ONAP) tiene a su cargo la preparación de los trabajos técnicos y los manuales operativos para la puesta en vigencia de la Ley, habiéndose iniciado su implementación en las oficinas recaudadoras del Estado, con el propósito de extenderla a otras áreas.

En cuanto a la reorganización administrativa, un diagnóstico realizado por especialistas del Instituto Ortega y Gasset de España con la cooperación de ONAP, ha servido de base para un proyecto de asistencia técnica del gobiemo de España en este campo, en coordinación con la Pontificia Universidad Católica Madre y Maestra (PUCMM).

Para la modernización de las aduanas se está ejecutando un proyecto con el Programa de Naciones Unidas para el Desarrollo (PNUD, mientras que el Banco Interamericano de Desarrollo (BID) ofrece asistencia en materia de reforma financiera y fiscal. El PNUD también 
ofrece asistencia a la Secretaría de Relaciones Exteriores para la modernización de este ministerio y su política exterior.

\section{Sociedad Civil}

La sociedad civil se ha convertido en el centro del debate sobre la democracia. Ello ha sido el fruto de la emergencia de una amplia gama de nuevos y viejos actores sociales organizados (asociaciones comunitarias de base, entidades empresariales, sindicales, campesinas, profesionales, religiosas, de mujeres, ecológicas, entre otras) y de instituciones de servicio sin fines de lucro, que actúan con un creciente protagonismo fuera del marco del Gobierno y de los partidos políticos.

Estos actores han ganado una presencia notoria en la definición de los temas de la agenda pública, constituyéndose en fuente de opinión e iniciativas ciudadanas, en grupos de presión ante los órganos gubernamentales y en plataforma institucional para la prestación de servicios sociales, supliendo con ello muchas de las carencias de las agencias del Estado.

Uno de los mayores logros alcanzados por este variado conglomerado de organizaciones e instituciones sociales - apuntalado por la validación técnica y financiera de los organismos internacionales- fue la definición del Plan Decenal de Educación que, tras un proceso de concertación pluralista y multisectorial, fue adoptado por el Estado. Dicho Plan tiene como objetivo transformar la calidad y cobertura de la educación básica.

Otro logro fue la estructuración de una Agenda Nacional de Desarrollo promovida, entre otros, por el Grupo de Acción por la Democracia, (GAD) y cuyas metas principales fueron asumidas por los partidos políticos y los candidatos presidenciales durante la campaña electoral de 1996. Por su parte, la sociedad civil dominicana ha jugado un papel protagónico en coyunturas políticas críticas, como fue la vivida a raiz delas eleccionesde 1994. Este esel casode organizaciones como Participación Ciudadana, que coordinó la Red Ciudadana de Observadores Electorales en los comicios presidenciales de 1996.

El importante papel jugado por la sociedad civil se explica por la confluencia de varios factores. A saber, la pérdida de credibilidad del 
sistema político, debido a su ineficacia en la solución de las demandas sociales y al distanciamiento entre representantes y representados en el desempeño de las funciones electivas; la capacidad de los actores sociales para constituirse en interlocutores válidos frente al Gobierno y los partidos, y participar en la construcción de una democracia sustantiva; su interés hacia la autogestión; la demanda de cambios que sustituyan los valores autoritarios y las prácticas excluyentes de la cultura política, por otros democráticos y participativos.

La sociedad civil dominicana se encuentra en una fase de madurez que pretende conjugar su perfil heterogéneo con ciertos niveles de articulación, particularmente en la coordinación de sus componentes, como es el caso de las organizaciones de base y un sector de las ONG's. Sus actividades se orientan hacia la exclusión de las entidades menos articuladas en favor de las que poseen un mayor peso social, las cuales asumen con frecuencia la representación del conjunto de la sociedad civil. Este rasgo ha sido motivo de controversia y de cierta tensión entre dichas entidades y los actores políticos, que las perciben como instrumentos de los sectores poderosos (empresariales, eclesiásticos y extranjeros). Por otra parte, la elevada dependencia de las ONG's de financiamiento internacional las hace particularmente vulnerables, y hace abrigar dudas sobre su capacidad ejecutoria en el mediano o largo plazo.

\section{Medios de Comunicación}

La historia dominicana es una confirmación más de que los medios impresos y los electrónicos florecen en las sociedades democráticas. El desarrollo del diarismo y el auge de la radio y la televisión se corresponden con exactitud al comportamiento del proceso democrático.

Una revisión de las normas que organizan el sector de la comunicación y orientan el papel del Estado muestra que son obsoletos porque responden a realidades superadas hace ya varias décadas, $o$ surgieron en momentos de excepción yno comoproducto de un ejercicio de reflexión y el debate democrático. República Dominicana tiene diez diarios, nueve de circulación nacional y uno de circulación regional. Seis son matutinos y cuatro vespertinos. 
El escaso nivel educativo, la poca tradición de lectura y los bajos ingresos de la mayoría de la población explican el reducido nivel de lectoría de diarios en República Dominicana. Actualmente se estima una circulación global de menos de 200 mil ejemplares diarios, equivalentes a una tasa de aproximadamente 38 ejemplares por cada mil habitantes. El estimado de la UNESCOpara 1980 fue de 42 ejemplares por cada mil habitantes.

Desde hace tres décadas el Estado Dominicano no había tenido un periódico de su propiedad, con excepción del corto periodo de seis meses, entre abril y octubre de 1996, en que el Banco Central fue posesionario del diario El Siglo.

Actualmente ninguna autoridad tienen información precisa sobre el número de estaciones de radio, dado que muchas emisoras operan ilegalmente o han sido trasladadas sin autorización de una población a otra, lo que hace dificil evaluar el estado de la asignación y uso de las frecuencias. Sin embargo, ya en 1985 un estudio realizado por técnicos japoneses cuantificaba las radioemisoras en 203, de las cuales 121 operaban en Amplitud Modulada y 82 en Frecuencia Modulada. El $92 \%$ eran comerciales y el $64 \%$ religiosas y el $1 \%$ estatales.

En cuanto a la televisión, ahora operan siete canales de alcance nacional. En la banda UHF opera, con programación dominicana, una docena de canales de televisión, que además transmiten a través de la empresa Telecable Nacional. En las principales ciudades del país también operan otras compañías privadas de telecable, que además de ofertar una programación internacional, tienen canales locales de televisión.

El estado Dominicano es propietario de tres frecuencias de televisión en $\operatorname{VHF}(4,5$ y 12) que utiliza en una única programación por vía de Radio Televisión Dominicana, pero que en su gestión administrativa opera igual que las estaciones privadas.

La cultura fundamentalmente audiovisual, la facilidad de acceso a las estaciones de radio y televisión y su bajo costo relativo determinan que los medios electrónicos sean los de mayor penetración en la población dominicana, aunque los periódicos siguen teniendo el dominio en la influencia sobre los niveles de decisión política y económica, 
porque además de sus propias posibilidades, son uno de los principales sustentantes y fuentes de información de la programación informativa y de opinión de los medios electrónicos.

En la República Dominicana se expresa una gran pluralidad a través de los medios de comunicación social. La libertad de información es relativamente alta, si se compara con la prevaleciente en otros países de la región.

\section{Guías para la Reforma del Sistema Político Dominicano}

El proceso de reforma política pendiente en la República Dominicana responde a la necesidad que impone la transición que vive el país, de cara al fortalecimiento y consolidación de la democracia, como un orden más participativo y funcional. La agudización de esta necesidad viene dada por un contexto caracterizado por una mayor pluralidad de actores que reclaman la apertura de espacios de participación, en su lucha continua por la superación de las deficiencias seculares de nuestro subdesarrollo en materia de empleo, educación, salud, y protección de los derechos humanos y ciudadanos.

A las condiciones internas se suman los desafios provenientes de un contexto internacional que globaliza la economía, haciendo más perentoria la necesidad de adecuar la estructura económica y el marco institucional a los imperativos que emanan de la modernidad. Por estas razones, estamos compelidos al abandono de los esquemas tradicionales y la adopción de las pautas modernas de organización de la vida económica e institucional. Los cambios se viven como un proceso acelerado de reconversión que encierra en si mismo la necesidad de reformas

El proceso de reforma cobró un impulso decisivo con el cambio de gobierno operado en agosto de 1996. El nuevo gobierno, presidido por el Dr. Leonel Fernández, propició un clima favorable a las reformas. Pero la efectiva ejecución de un programa de reformas requiere de un plan estratégico que ha de guiarse por principios generales que iluminen el tránsito hacia la consolidación de la democracia. Estos principios guías se detallan a continuación: 
- La reforma como un proceso integral:

La transformación del sistema político dominicano parte del postulado de que el proceso de reforma es una acción integral, en donde las áreas prioritarias para la reforma se relacionan entre sí dentro de una totalidad integrada, que requiere de una planificación global y acciones específicas.

- La reforma como un proceso para la racionalidad:

El sentido de las reformas políticas y la modernización del Estado está dirigido a elevar el nivel de racionalidad en las estructuras, normas y procedimientos orgánicos que operan en las diferentes áreas institucionales objeto de las reformas. Se trata, en consecuencia, de mejorar los niveles de articulación de cada área, así como su base tecnológica y los recursos humanos, a fin de hacerlas más eficientes y operativas en función de los objetivos y necesidades colectivas que les dan razón de ser.

- La reforma como un proceso multisectorial:

El planteamiento y ejecución de un proceso de reformas exige la concurrencia de los diversos sectores involucrados, así como, de los diversos estamentos interdisciplinarios que actúan en las diferentes esferas del Estado y de la sociedad civil. En consecuencia, la multisectorialidad y la multidisciplinaridad son rasgos consustanciales en un proceso de reformas democráticas.

- La participación y concertación política:

En un contexto democrático, abierto y transparente, el proceso de reformas tiene que entenderse como una acción participativa, en la cual, los actores involucrados tienen que estar presentes como elementos decisorios en una dinámica realizada mediante la concertación. La participación deviene como una condición necesaria para asegurar la eficacia en las decisiones que se adopten en el proceso. Al mismo tiempo, crea las bases necesarias para la legitimación de los mecanismos y sistemas que se van desarrollando con las reformas.

- La reforma como acción inducida por el Estado:

Elproceso de reformas políticas es similar al proceso de desarrollo: tiene que entenderse como una acción protagonizada por la sociedad civil y la sociedad política conjuntamente, aunque estimulada y mo- 
tivada por el Estado. Es la acción conjunta de estas fuerzas lo que hace viable un proceso de reforma integral, racional y participativa. acción:

La dinámica del proceso de reforma debe contemplar dos líneas de

- La articulación de intereses:

Consiste en disponer de un mecanismo que integre y articule los diferentes sectores políticos y sociales que inciden directamente en las reformas y que opere como un espacio de concertación que precipite el proceso. Este mecanismo se ha iniciado con la creación del Comisionado para la Reforma Judicial y la Comisión Presidencial para la Reforma y Modernización del Estado.

Para que estas comisiones cumplan su papel reformador y democrático, deben tomar en cuenta los siguientes criterios:

- la representatividad política y social de sus integrantes

- la separación de los poderes del Estado

- la coordinación de actividades con instituciones nuevas o existentes en los sectores público yprivado que comparten objetivos similares.

- la transparencia como norma de todas las ejecutorias

- Los espacios de concertación y difusión del proceso:

Para ampliar y generar el consenso, los trabajos de reforma deben acompañarse de un plan de actividades que promueva el debate y la difusión de iniciativas que sean de interés para distintos sectores de la sociedad dominicana. Se trata de abrir espacios de concertación entre representantes de los distintos poderes del Estado, de los partidos politicos, de las organizaciones sociales (empresariales, sindicales, profesionales, barriales), y de instituciones sociales importantes como las universidades y las iglesias.

Estos espacios de concertación y difusión para la legitimación de las reformas podrían abrirse en forma de foros sectoriales, talleres y jornadas de difusión, reuniones para la discusión y consulta sobre aspectos especiales de las reformas.

Finalmente, a este respecto se debe tener en cuanta el papel destacado que los medios de comunicación social desempeñan. 


\section{Posibilidades y Dificultades de la Reforma}

La estrategia para conducir un proceso de reformas tiene que ponderar las oportunidades y obstáculos que se presentan en el proceso político. En ese sentido, el mapa político que caracteriza actualmente la situación nacional determina un cuadro de oportunidades y limitaciones. Éste ha de servir de punto de partida para el diseño de una estrategia que conduzca hacia un proceso de reforma que viabilice la transformación y modernización de las estructuras institucionales del país.

En general, en las diversas fuerzas sociales, locales e intemacionales que inciden en la dinámica sociopolítica del país, se observa una tendencia favorable a ciertas reformas y proyectos o iniciativas para la modernización del sistema político. En este orden, se favorecen acciones de reforma a nivel constitucional, judicial y de la administración pública. De igual modo, se hacen planteamientos que favorecen las modificaciones del sistema electoral y los partidos políticos, así como el diseño de un marco legal que propicie la descentralización y el fortalecimiento del poder local.

Hay que destacar, sin embargo, que junto a las tendencias favorables existen obstáculos que se ponen de manifiesto en diversos sectores y grupos, y que cuestionan la forma y alcance de las reformas. El tradicionalismo, el clientelismo partidista y los intereses particulares o especiales constituyen serias trabas al proceso de reforma. En este sentido, un plan de reforma debe considerar las oportunidades y los obstáculos existentes.

\section{Oportunidades}

- Entre las oportunidades debe destacarse el cambio de gobierno ocurito el 16 de agosto de 1996, que abrió un proceso de cambio y apertura hacia una recomposición de las fuerzas sociales que favorecen las reformas.

- Las iniciativas del Presidente Leonel Fernández que pueden inducir a otros actores del proceso a desarrollar una disposición favorable al cambio y, específicamente, a las iniciativas en favor de la modernización. 
- La idea generalizada de que el nuevo contexto de globalización de la economía obliga a una adaptación e inserción del país a las nuevas condiciones del mercado mundial, especialmente en lo relativo a la reducción de los niveles de protección y subsidios de la economía.

- En el plano político-social habría que enfatizar también que las fuerzas partidarias coinciden en expresar la necesidad de reconversión y reforma. Por ejemplo, durante la campaña electoral de 1996 todos los partidos plantearon la reforma política como objetivo a alcanzar. Por su parte, distintos sectores sociales (organizaciones de tipo empresarial, sindical, profesional, cívico y religioso) comparten la idea de motivar los cambios políticos necesarios. Estos grupos favorecen, sobre todo, las reformas judiciales y administrativas que garanticen una mayor vigencia del estado de derecho y una mayor eficacia de la burocracia.

- Por otra parte, gobiernos amigos de la República Dominicana (España, Francia, Italia, y Estados Unidos), así como agencias internacionales (BID, PNUD, Banco Mundial, USAID) han expresado su disposición de contribuir con las reformas, o se encuentran ya prestando asesoría o financiamiento en proyectos de modernización institucional.

\section{Obstáculos}

- Entre los obstáculos debe enfatizarse la vigencia del tradicionalismo y la resistencia natural al cambio.

- Una cultura política que privilegia la centralización y la exclusión, y que determina orientaciones y comportamientos contrarios a la apertura y a la participación de los actores vinculados al proceso.

- El fuerte peso que ejercen los intereses particulares y las posturas individualistas en las decisiones colectivas y en la actitud de los dirigentes partidarios. En este aspecto intervienen, de manera especial, los intereses de empresarios privilegiados y los cálculos electorales de los dirigentes políticos, quienes se movilizan más en función de ventajas particulares y personales que por motivaciones que garanticen el interés general.

- Aunque el apoyo internacional, tanto en asistencia económica 
como en ayuda técnica, es crucial en la implementación de un plan de reforma política, existe la posibilidad de que este apoyo sea interpretado por ciertos sectores como una injerencia extranjera.

- Finalmente, existe la posibilidad de que el gobierno que preside Leonel Fernández margine la agenda de la reforma política en favor de otras iniciativas. Con un Congreso adverso al Ejecutivo, y graves problemas económicos por enfrentar en el país, la posibilidad de que la agenda de reforma política se margine es lamentablemente alta. Sin embargo, el incentivo para gobernar eficazmente deriva de que en 1998 habrán elecciones congresionales y municipales.

- En el momento actual debe evitarse que la tendencia a lo coyuntural impida avanzar en lo global del proceso de reforma, así como también la tendencia a la búsqueda de soluciones entre cúpulas a los problemas que enfrenta el país en la modernización y reforma política.

A pesar de las dificultades enumeradas, el balance para el impulso de iniciativas de reformas que viabilicen y consoliden el proceso de modernización e institucionalización del sistema político dominicano, es positivo. Vale resaltar que la efectividad en la conducción de las fuerzas sociales para la realización del cambio, dependerá de la destreza que imprima el liderazgo nacional, especialmente el Gobiemo, y de la disposición que muestre para aplicar un modelo integral de reformas con capacidad decisoria. 


\section{PROPUESTAS DE REFORMA POLÍTICA}

\section{Jerarquización de Prioridades}

En este momento parece conveniente, sugerir una jerarquización de prioridades, tanto entre las distintas áreas del sistema político, como entre los diversos aspectos contemplados por cada una de ellas.

Esta jerarquización se ha determinado tomando en cuenta los siguientes factores: el impacto que tendría una reforma específica en facilitar otras reformas; el nivel de consenso existente en torno a la reforma propuesta; la necesidad sentida por el cuerpo social de introducir nuevos cambios; la capacidad de incorporar otros sectores sociales y políticos al proceso de reforma; y las facilidades u obstáculos para emprender dicho proceso. Un último factor importante tomado en consideración ha sido si la reforma en cuestión se puede realizar sólo mediante medidas administrativas o si requiere de leyes o modificaciones constitucionales.

He aquí la jerarquía de prioridades sugerida:

- En un gobierno con minoría congresional, las estrategias con mayores probabilidades de éxito, al menos a corto plazo, son las que no requieren de sanción legislativa. Por esta razón, el mejoramiento inmediato de la Administración Pública (gobierno central y local, con sus respectivas dependencias), así como la reorganización técnico-administrativa de los Poderes Legislativo y Judicial constituyen los que podríamos considerar una "prioridad de prioridades". Dado que la ley de Servicio Civil y Carrera Administrativa y su Reglamento 
ya han sido promulgadas, no se requiere más que su implementación, sin necesidad de legislación nueva alguna. En la reforma administrativa, el esfuerzo debe orientarse a mejorar los serviciospúblicos en base a cambios organizativos que mejoren la calidad del personal y el funcionamiento institucional Una vez que los organismos internacionales de financiamiento hayan aprobado los fondos necesarios para estos proyectos, tan sólo se requiere de la decisión de los representantes de los poderes del Estado para impulsar estas reformas. La reforma administrativa, finalmente, se puede esperar que ejerza un efecto inmediato en todo el sistema político nacional.

- La Reforma del Sistema Electoral ocupa también un lugar preponderante en toda consolidación democrática. Específicamente en la República Dominicana, durante las elecciones de 1996 se implementaron las reformas electorales que habían sido aprobadas en 1994 y 1995. Si bien es cierto que dichas reformas tuvieron un efecto positivo en el proceso electoral, se reconoce la necesidad de modificar sin más demora la Ley Electoral, con el fin de garantizar un desarrollo adecuado de las elecciones congresionales y municipales de 1998

Los actuales miembros de la JCE sometieron al Congreso un Proyecto de Ley de Reforma al Sistema Electoral que debe servir de base para llevar a cabo reformas que mejoren y consoliden los futuros procesos electorales dominicanos.

Una razón importante para priorizar la reforma del sistema electoral es su impacto reformador en otras instancias. En el proceso de modificación del sistema electoral debería aprovecharse la oportunidad para hacer reformas en los métodos de elección de los congresistas y los representantes municipales, así como establecer una Ley de Partidos.

La Reforma del Sistema Judicial. Institucionalizar el sistema judicial es una labor de alta prioridad para consolidar el sistema democrático. Los sectores organizados de la sociedad dominicana coinciden en este objetivo. El Presidente Leonel Fernández ha tomado en consideración la importancia de esta reforma y, a tal fin, ha nombrado un Comisionado para la Reforma Judicial. Asimismo, varias instituciones nacionales han enfatizado la importancia de esta reforma en sus agendas de modernización y democratización (FINJUS, GAD, y la 
Fundación Siglo XXI, entre otras), e instituciones internacionales y gobiemos amigos han abierto la posibilidad de financiar la reforma judicial (BID, USAID, el gobierno español, francés e italiano). No todaslas reformas podrán ejecutarse simultáneamente. Debería comenzarse por hacer efectivas las disposiciones de la reforma constitucional de 1994, y entre ellas, la aplicación de los métodos de selección de los jueces.

El fortalecimiento del poder local mediante la Reforma Municipal constituye otro eslabón importante en el proceso de modernización y democratización de la sociedad dominicana. Los estudios disponibles y el programa de descentralización que realizan conjuntamente el PNUD, el Secretariado Técnico de la Presidencia y la Liga Municipal Dominicana, requieren para su aplicación del apoyo del Gobierno y el Congreso.

La Reforma Constitucional resulta crucial para establecer bases sólidas a nivel institucional en el proceso de democratización. La actual situación política del país, caracterizada por la fragmentación del poder político (un Ejecutivo sin mayoría congresional) y la carencia de un liderazgo sólido en los tres partidos mayoritarios, dificultan la puesta en marcha de un proceso de reforma constitucional en el corto plazo. Esaconsejable, por tanto, que la reforma constitucional se posponga por lo menos hasta 1998 .

El proceso de reforma que directamente toca a la sociedad civil depende fundamentalmente del desarrollo de las organizaciones sociales. Sin embargo, una verdadera incorporación de estas organizaciones en el proceso de reforma política depende de las oportunidades que ofrezca el Estado para su participación.

Conviene indicar que existen reformas factibles de ser aplicadas conjuntamente en distintas áreas, como por ejemplo el establecimiento de una carrera civil, judicial, legislativa, y municipal; o la implementación de programas de formación para legisladores, jueces, munícipes, personal administrativo y dirigentes políticos. La aplicación de reformas coincidentes en distintas áreas resulta beneficiosa, ya que propicia el acercamiento y la coordinación de diversos sectores del sistema político. 


\section{La Reforma Constitucional}

\section{Recomendaciones}

- Se recomienda no propiciar un proceso de reforma constitucional antes de las elecciones de 1998, pues existe una gran posibilidad de que dicho proceso culmine en una contra-reforma. La única modificación constitucional que se efectúe antes de 1998 debe ser sobre el mecanismo de reforma a la Constitución: se trata del título XIII de la Constitución (De las Reformas Constitucionales).

- Debería adoptarse el mecanismo de reforma constitucional que mejor garantice una dinámica participativa y deliberativa en la solución de los aspectos constitucionales. Esto impone el inicio de un debate profundo y sistemático sobre los posibles mecanismos de reforma constitucional, en el que se adopte el que mejor garantice una dinámica democrática.

- Se sugiere que el actual mecanismo de modificación a la Constitución sea reemplazado por una Asamblea Constituyente electa por el pueblo en 1998, mediante listas de candidatos sometidas por los partidos políticos y diversas organizaciones de la sociedad civil. Las reformas que apruebe la Asamblea deberán ser sometidas a la sanción popular vía el referéndum. Esta modalidad requiere, además, que se establezca la composición de la Asamblea, su forma, el tiempo de duración de sus trabajos, la organización de los mismos, entre otros temas.

- La Asamblea Constituyente electa debería tener como objetivo la realización de una reforma suficiente del sistema político dominicano, lo cual no implica que todas las instituciones deban ser reformadas. Hay que evitar que se repita la experiencia de 1994, cuando se implementaron reformas parciales sin que se evaluaran debidamente los efectos que esos cambios institucionales parciales tendrían sobre el funcionamiento del sistema político en general.

\section{Aspectos a considerar en una reforma constitucional}

- El tipo de régimen político (presidencial, semi-presidencial, parlamentario) que, dadas lavigente organización partidaria ylas características de las luchas políticas en el país, pueda ofrecer las condicio- 
nes institucionales más propicias para la consolidación democrática, la gobernabilidad y la estabilidad política.

- Los mecanismos de participación y representación de los ciudadanos en el sistema político, con el propósito de fortalecer la fiscalización de los gobernantes por los gobernados.

- Los órganos del sistema judicial a la luz de las reformas introducidas en 1994, a fin de profundizar la independencia, la integridad institucional y la profesionalización de este poder del Estado. Un punto a considerar de manera particular es el relativo al sistema de control de la constitucionalidad de las leyes.

- Los mecanismos de protección de los derechos ciudadanos con miras a fortalecer los existentes o a crear otros que fortalezcan el estado de derecho.

- Los órganos de poder provincial y municipal, y su relación con el gobierno central Aunque éste es un tema cuyas particularidades deben ser decididas dentro del ámbito legislativo ordinario, los parámetros generales relativos a la distribución del poder territorial pueden ser establecidos en la Constitución.

- El sistema electoral para adecuarlo a la distribución poblacional del país y a métodos de elección que aseguren un mayor nivel de participación y representación, así como, la eficacia de los cargos públicos.

\section{Estrategias a seguir}

- Es necesario crear una dinámica en la sociedad civil dominicana que impida que los partidos con mayoría congresional para reformar la Constitución, tomen el camino de la contra-reforma. Deben crearse condiciones en la opinión pública que sensibilicen a los actuales legisladores a favor de una reforma constitucional vía una Asamblea Constituyente.

- Celebración de eventos políticos y académicos dedicados a debatir diferentes opciones de reforma a la luz de las teorías constitucionales, las experiencias comparadas y la propia realidad dominicana. 
- Lograr que el Presidente de la República reafirme su posición en cuanto a la necesidad de que se modifique el mecanismo de reforma.

- Identificar grupos de legisladores que favorezcan la reforma constitucional en el momento actual, con miras a apoyarles y auspiciar acciones coherentes entre ellos.

\section{Acciones Alternativas}

- Si la idea de modificar el mecanismo de reforma constitucional previo a cualquier reforma de fondo resulta inviable, la reforma constitucional debería realizarse bajo el mecanismo vigente, pero por los legisladores electos en 1998. Habrá, en todo caso, que tomar medidas adicionales para evitar que los legisladores decidan sobre la cuestión constitucional sin tomar en cuenta el sentir de la sociedad.

- Posponer la reforma constitucional para que la asuma el Congreso electo en 1998 requerirá de algunas concesiones a los partidos que hoy tienen mayoría congresional, pudiéndose incluir acuerdos sobre la financiación de los partidos políticos, la creación de distritos electorales, y lo relativo a la reducción del porcentaje que establece la Constitución ( $50 \%$ ) para ganar en la primera vuelta.

- En caso de que los legisladores actuales ignoren tanto la demanda de que se modifique el mecanismo de reforma constitucional como la demanda de que la reforma constitucional se posponga para después de 1998 y, en consecuencia, procedan a enmendar la Constitución, habría que coordinar un gran esfuerzo en el que participen organizaciones políticas y sociales para facilitar y motivar la participación ciudadana en los debates congresionales. Además, habría que desplegar un esfuerzo para que los legisladores no impongan una contrareforma.

\section{Oportunidades}

- El PLD favorece que se posponga la reforma constitucional debido a su escaso peso congresional en la actualidad.

- Parte de los legisladores del PRD y el PRSC se oponen a una revisión constitucional en este momento. 
- Importantes grupos organizados de la sociedad civil (empresarios, obreros, profesionales) se oponen a una revisión constitucional en la actualidad, y les preocupa la posibilidad de que se realice una contrareforma.

\section{Obstáculos}

- Algunos legisladores del PRSC favorecen una modificación de la Constitución por el actual congreso. Igual ocurre con algunos legisladores del PRD.

- La parte de la sociedad civil que apoya la rápida modificación parcial de la Constitución podría, aún de forma no intencionada, contribuir a la contra-reforma.

- Existen diversos proyectos de leyes de mucha importancia para la economía dominicana, que compiten con una agenda de reforma política. Aunque éste sea un factor que ayude a disminuir la posibilidad de una contra-reforma, también limita la capacidad de acción del Congreso para modificar el mecanismo de reforma de la Constitución, que debería realizarse antes de las elecciones de 1998.

\section{Sistema Electoral}

\section{Recomendaciones}

- El sistema electoral dominicano requiere de una revisión a fondo de sus aspectos orgánicos (estructurales, funcionales, administrativos), normativos, procedimentales y operativos, a fin de compendiar la experiencia acumulada desde las reformas de 1992 hasta la fecha; prepararlopara lastareas definidasdecara a las eleccionescongresionales y municipales de 1998, y para la posible elección de una Asamblea Constituyente ese mismo año; así como, para incorporar reformas de más largo alcance.

- Las reformas al sistema electoral deben orientarse a garantizar una mayor representatividad y funcionalidad de las cámaras legislativas y los ayuntamientos (fortaleciendo el Poder Legislativo y consa- 
grando el Poder Municipal); a definir nuevos mecanismos de participación, supervisión y revocación de mandato a cargo de la sociedad civil y de la ciudadanía; y a perfilar un Poder Ejecutivo moderno y eficaz, más colegiado, descentralizado y, por tanto, más democrático en el ejercicio del poder.

- La revisión debe realizarse a la luz de las reformas incorporadas a la Ley Electoral en 1992 y 1995, y en base a la reforma constitucional de 1994

- Se plantea la necesidad de un diagnóstico de la JCE que compile evaluaciones realizadas hasta al momento por consultores nacionales y extranjeros, y actualice el estado de situación del organismo y sus dependencias, a fin de formular recomendaciones a una escala operativa.

\section{Aspectos a tomar en cuenta en una revisión a la Ley Electoral}

La reforma a la Ley Electoral de cara a la realización de los comicios congresionales y municipales en 1998 y de las elecciones presidenciales en el año 2000, debe contemplar los siguientes aspectos:

- El sistema de doble vuelta: se ha planteado la reducción de la mayoría absoluta del $50 \%+1$ de los votos en la elección presidencial, a una mayoría calificada de $40 \%+1$, o de $45 \%+1$, Se ha propuesto, además, el acortamiento del tiempo (actualmente 45 días) entre la primera y la segunda vuelta.

- Elecciones congresionales y municipales separadas: debe analizarse si se va a mantener el plazo de 2 años que separa la elección presidencial de la congresional y municipal, según la versión aprobada por la reforma constitucional de 1994 , o si se harán coincidir en un mismo año aunque celebrada de manera separada. Como es un tema con pros y contras, lo fundamental debe ser agotar un proceso amplio de discusión.

- La creación de los Distritos Electorales: la creación de distritos electorales para la elección de diputados y regidores en las grandes y medianas circunscripciones, supone la estructuración de los distritos (delimitación de su radio fisico, distribución correlativa de las mesas electorales y, por tanto, de los electores que los conformarían). La 
adaptación de la organización partidista con el fin de seleccionar los candidatos y desarrollar el trabajo electoral. Las acciones a realizar incluyen trabajostécnicos previos, así como, consultas con los partidos y los funcionarios de la JCE.

- En lo referente a una Ley de Partidos cuyo objetivo consistiría en formular una normativa que garantice la institucionalización de los partidos, ya se indicó en el apartado anterior que se presentan dos posibilidades, sea mediante una legislación especial sobre partidos políticos, o mediante un ampliación de la Ley Electoral.

- Formalización del sistema de elecciones primarias internas en los partidos, estipulándolo en la Ley Electoral y elaborando un Reglamento de Primarias que sirva de marco para su implementación por cada partido. Asimismo, la fijación de un período de primarias dentro del calendario electoral.

- Establecimiento en la Ley Electoral de una nueva normativa para el financiamiento de los partidos, que contemple la realidad de las diferentesfuentes de financiamiento de las campañas, establezca regulaciones realistas y promueva la transparencia en la identificación de las fuentes y en la administración de los recursos.

- Elaboración de reglamentos que regulen la campaña electoral, la propaganda, el acceso a los medios de comunicación (incluyendo los medios estatales), el funcionamiento de las organizaciones de apoyo, la observación electoral a nivel nacional e intemacional, y otros aspectos relativos al proceso electoral.

- A nivel organizativo y operativo de los organismos electorales, debe observarse el deslinde orgánico de las tres funciones básicas que tienen a su cargo los miembros de la JCE: administrativa, normativa y jurisdiccional, así como, la posibilidad de modelos alternativos de distribución y articulación de dichas funciones; definir el rol del Director General de Elecciones, sus dependencias y relación con la JCE; proceder a una adecuación orgánica, funcional y administrativa de la vieja Dirección de la Cédula de Identidad Personal al nuevo sistema de identificación electoral; elaborar e implementar un programa de modernización y depuración del sistema; defmir la ubicación del Centro de Cómputos dentro del organigrama de la JCE, dado el carácter 
sensible de su función, el historial de conflictos asociados a su acceso por parte de los partidos políticos y los observadores electorales, y los intentos y alegaciones de manipulación; evahuar el funcionamiento de las Juntas Municipales y de la Junta del Distrito Nacional, a fin de definir modelos más modernos y funcionales que refuercen la capacidad operativa de estas estructuras.

- Establecimiento de la carrera electoral. A fin de profesionalizar las funciones electorales, se requiere establecer dicha carrera, ya que la misma no está contemplada dentro de la Ley de Servicio Civil y Carrera Administrativa.

\section{Estrategias a seguir}

- Contratar estudios técnicos para la realización de un diagnóstico de la organización electoral y de la JCE, a fin de formular recomendaciones a una escala operativa.

- Organizar ciclos de talleres para evaluar los niveles de capacitación del personal de la JCE, de los partidos políticos y de las organizaciones de apoyo de la sociedad civil, y con los directivos de las cámaras legislativas para discutir un Plan de Trabajo en materia de reforma y modernización del sistema electoral. Además, estructurar un equipo de seguimiento que se encargue de impulsar los limeamientos del Plan de Trabajo aprobado por la JCE, los partidos políticos y el Congreso.

- Las acciones de tipo organizativo-administrativo en las instancias de la JCE son factibles de realización, sin que para ello se requiera de cambios constitucionales. Sin embargo, las derivaciones que pudieran emanar de este proceso de modernización contemplan algunas enmiendas legales, como por ejemplo, un mayor deslinde de las tres funciones que concentra la JCE (admimistrativa, reglamentaria y jurisdiccional) y los requisitos para ser miembro titular y suplente de dicho organismo.

- Debe realizarse una evaluación del proceso electoral de 1996 que contribuya a estructurar el plan de reforma y modernización. Esta evaluación debe comprender los siguientes aspectos: el estado de situa- 
ción del padrón electoral, el funcionamiento de los colegios electorales cerrados, la dinámica del proceso de votación, el procesamiento y divulgación de los resultados, la observación electoral nacional e internacional, y los métodos de presentación y resolución de impugnaciones. La ejecución de esta acción sólo requiere de una iniciativa debidamente estructurada en la dirección propuesta, a cargo de un ente con suficiente reconocimiento entrelos actores a ser convocados(JCE, partidos, entidades de apoyo y legisladores). Dado que la JCE exhibió logros significativos en la organización del proceso electoral de 1996, esta imiciativa podría contar con un nivel de respaldo adecuado.

\section{Acciones Alternativas}

- De no realizarse una reforma a fondo del sistema electoral antes de las elecciones congresionales y municipales de 1998, por lo menos se deben identificar y mejorar los asuntos que resultaron problemáticos en 1996.

\section{Oportunidades}

- Tras los comicios de 1996, la JCE sometió al Congreso Nacional un proyecto de ley de reforma al sistema electoral. Este documento constituye un reconocimiento formal de la necesidad de introducir reformas y abre la posibilidad del debate electoral a nivel congresional y nacional El trabajo meritorio de la JCE en el proceso electoral de 1996 le otorga particular credibilidad a su propuesta de reforma.

- Por su parte, los partidos han ido desarrollando diferentes modalidades de definición de sus candidaturas, abriéndose cada vez más el compás en dirección a la celebración de alguna modalidad de primarias internas, siendo el primero en llevarlas a cabo el Partido Revolucionario Social Cristiano (PRSC). Este proceso ha sido producto de las propias necesidades de evolución estatutaria de los partidos, de la búsqueda de salidas orgánicas a los conflictos internos y de su adecuación a las demandas de una mayor democratización que surgen de la propia sociedad civil, las cuales preceden al eventual establecimiento de normas legales que los obliguen a ello. Los liderazgos emergentes en los partidos políticos han jugado un papel importante en impulsar estos cambios. 
- Las acciones de la JCE y de los partidos, junto a las nuevas demandas de participación surgidas desde la sociedad civil, al desarrollo de prácticas de concertación social y la expansión de los valores democráticos, hanido perfilandouna agenda de reforma política, dentro de la cual el sistema electoral es de suma importancia.

\section{Obstáculos}

- A pesar de los importantes avances alcanzados en el proceso electoral de 1996, inchuida la observación electoral por la Red Ciudadana de Observadores Electorales a nivel nacional, todavía es mucho lo que debe hacerse para la profundización del ordenamiento jurídico del proceso electoral, así como de los propios organismos electorales.

- En los partidos predomina una cultura de desconfianza y resistencia a su fiscalización. Por su parte, las cúpulas partidistas se han beneficiado de la falta de institucionalización de los partidos y del sistema electoral.

- Los legisladores, con poder para modificar el sistema electoral, establecen acuerdos con las élites partidarias. Hay una tendencia a festinar proyectos de leyes o a prolongar su aprobación.

\section{Partidos Políticos}

\section{Recomendaciones}

- La modemización del régimen de partidos políticos se plantea como un proceso en el que deben promoverse las siguientes acciones prioritarias: concertación interpartidaria, formación y capacitación política y cambios en el marco normativo.

- Debe crearse un mecanismo de encuentro interpartidario, promovido por la sociedad civil, que abra un espacio para que la diligencia partidaria y de la sociedad civil establezcan un canal permanente de comunicación y diálogo, y logren el consenso necesario para impulsar las reformas. 
- Lospartidosdeben adoptarun mecanismode formación y capacitación política que permita a su dirigencia asimilar e integrar en su quehacer las herramientas científicas, tecnológicas, ideológicas y éticas que pongan a dicha dirigencia en condiciones de abordar con destreza técnica y práctica las temáticas relevantes de la agenda nacional.

- Debe establecerse un marco jurídico constitucional o legal que garantice una dinámica interpartidaria más ágil, eficiente y funcional, y dotada de una mayor presencia y contenido ético. De esta manera se consolida el proceso interpartidario y se garantizan procesos electorales de mayor eficiencia y confiabilidad.

- Se recomienda la elaboración y aprobación de una legislación sobre Partidos que contemple, entre otros aspectos, el financiamiento de los partidos, el uso de los medios de comunicación, y la democracia interna de los partidos. El objetivo es dotar a los partidos de un marco jurídico que tienda a crear condiciones de igualdad competitiva.

- Un proceso de concertación entre los partidos que facilite la puesta en marcha de las reformas al régimen de partidos de cara a la consolidación democrática, debe partir, dadas las circunstancias del contexto actual dominicano de dos hechos recientes: la designación de la Comisión Nacional para la Modernización y Reforma del Estado por parte del Poder Ejecutivo, y la propuesta de modificación a la Ley Electoral presentada por la JCE. Estos dos hechos deben considerarse como potenciales precipitadores del proceso de reforma del régimen partidario.

\section{Estrategias a seguir}

- Foro interpartidario para la concertación sobre la reforma de los partidos políticos. El Foro convertirá en propuestas consensuadas las demandas colectivas sobre las cuales trabajen las comisiones de los partidos. Este foro deberá contar con un apoyo técnico profesional que provea los estudios de base correspondientes.

- Eldebate delas comisionesinterpartidarias seorganizaría mediante una metodología basada en la siguiente dinámica: reuniones de los 
delegados según agenda con temas específicos de discusión, preparación de propuestas por técnicos especializados, análisis y discusión de las propuestas, selección delas opciones de mayor consensoy preparación.

- Presentación del proyecto de reforma del Foro a la diligencia de los partidos y de las organizaciones representativas de la sociedad civil, para su conocimiento, socialización y puesta en ejecución.

- Celebración de un taller sobre la reforma del régimen partidario, donde se analice tanto el contenido de la reforma, como la forma de inserción al sistema legal dominicano.

- Establecimiento de un Instituto de Formación Política: se trata de proveer a los partidos de un centro en el cual la dirigencia y la juventud partidaria o simpatizante puedan recibir, mediante una tecnología y metodología educativa modernas, una capacitación que los ponga en condiciones de ejercer sus tareas políticas de forma eficaz y competitiva. Este proyecto podría viabilizarse a través de un acuerdo con las universidades.

- El Instituto de Formación Política no compite con las Escuelas de Cuadro de los partidos. Se concibe como un centro postsecundario de educación de adultos, dirigido a fortalecer la cultura y la praxis político-partidaria de segmentos poblacionales de donde regularmente surge el liderazgo político.

- El Instituto no deberá depender ni de los partidosni del Congreso Debe concebirse como un centro que, aunque sea financiado por el Estado, tenga autonomía y esté abierto a todos los sectoresinteresados.

\section{Acciones alternativas}

Como quedo evidenciado anteriormente, si no se dieran las acciones sugeridas para lograr la aprobación de una legislación específica sobre lospartidos, se tratarían de inchuir sus principales aspectos dentro de la nueva Ley Electoral, entendiendo a ésta como una especie del código electoral. 


\section{Oportunidades}

- En los tres partidos mayoritarios, PRD, PLD y PRSC, se están dando tendencias favorables a reformas y acciones para la modernización de los partidos políticos. Se plantea la necesidad de reformas en el interior de los partidos con miras a su reestructuración y modernización para una vida política más democrática y competitiva.

- La mayor competitividad de los tres partidos mayoritarios por mantener una cuota de poder político también favorece una reforma que garantice mayor igualdad de oportunidades.

\section{Obstáculos}

- Resistencia al cambio y desconfianza de la diligencia tradicional de los partidos políticos. El tradicionalismo, el clientelismo y los intereses de grupos consolidados en el dominio de los partidos constituyen serias trabas a los procesos de reforma.

- La tendencia oligárquica y la orientación burocratizada, movida por el clientelismo y la aspiración individual por posiciones electivas en la diligencia de los partidos, obstaculiza la dinámica democrática.

- Escasa preparación técnico-profesional de los dirigentes tradicionales de los partidos para una dinámica competitiva abierta e institucionalizadora.

- Las circunstancias indicadas refuerzan el aislamiento de los partidos respecto a la sociedad civil, que reclama cambios en la operatividad de los partidos políticos.

\section{$\underline{\text { Poder Judicial }}$}

\section{Recomendaciones}

- La reforma constitucional de 1994 incluye elementos que establecen líneas macro de prioridad y acción para el sector, pero que deben complementarse con otras reformas en áreas específicas de la administración de la Justicia. 
- En el ámbito de las reformas debe tenerse en cuenta su integralidad, esto es, la necesidad de que el problema de la administración de la justicia se aborde como un todo, aunque no necesariamente de manera simultánea.

- Al momento, existen diversos planteamientos sobre qué reformar y cómo conducir el proceso de reforma del sistema judicial. Mientras llega el consenso, hay acciones específicas que pueden ir allanando el camino a los planteamientos sobre la administración de la justicia.

\section{Estrategia a seguir}

- Discutir y aprobar el reglamento del Consejo Nacional de la Magistratura, que constituirá el brazo operativo de la institución que designará los jueces de la Suprema Corte de Justicia.

- Reformar la Ley de Organización Judicial, establecer la reestructuración organizativa y administrativa del Poder Judicial, y elaborar un estatuto del Ministerio Público que garantice su independencia funcional del Poder Ejecutivo. Discutir y aprobar la Ley de Carrera Judicial, y crear la Escuela Nacional de la Magistratura.

- Revisar la Ley Orgánica de la Suprema Corte de Justicia a fin de dotarla de facultad reglament aria, lo cual, deberá contemplar los siguientes aspectos: diseñar una estructura eficaz, crear una tercera sala que se ocupe de las materias constitucional, tributaria y contencioso-administrativa, aumentar el número de magistrados, supervigilar la administración de la justicia y mejorar las funciones administrativas.

- Aprobar la Ley de Administración Presupuestaria del Poder Judicial que le otorga el 6\% del Presupuesto de la Ley de Ingresos y Gastos Públicos. Revisar los salarios e implantar un sistema de compensaciones para los magistrados y funcionarios del orden judicial.

- Establecer un régimen de garantías constitucionales, elaborar políticas y legislar para eliminar la discriminación contra la mujer, y promover el cumplimiento de las disposiciones del Código para la Protección de Niñas y Adolescentes. Para cumplir estos objetivos se requiere crear los tribunales necesarios, capacitar los magistrados y personal auxiliar, y contar con la asistencia técnica a la Policía. 
- Educación ciudadana sobre derechos y garantías, y concientización sobre la necesidad de las reformas y politicas contra la corrupción. Para esto se sugiere la realización de campañas sencillas y masivas de difusión de los derechos y obligaciones, y el funcionamiento de los organismos estatales, así como, campañas institucionales para ilustrar sobre los perjuicios de la corrupción.

\section{Oportunidades}

- La creación del Comisionado para la Reforma y Modernización de la Justicia abre un espacio institucional para impulsar el proceso de reforma judicial.

- La sociedad civil, por su parte, ha mostrado gran interés al presentar propuestas de solución a la crisis de la justicia, entre ellas, las propuestas de la Fundación Institucionalidad y Justicia (FINJUS). Estas acciones han motivado que otras organizaciones, como el Consejo Nacional de la Empresa Privada (CONEP) y el Grupo de Acción por la Democracia (GAD), consideren la reforma judicial como una de las prioridades de la agenda para lograr la institucionalización y modernización del Estado. Asimismo, están emergiendo nuevas instituciones bajo la bandera de la reforma judicial, como es el caso de la Asociación de Abogados Empresariales (ADAE).

- La velocidad de las reformas estará directamente relacionada con la capacidad de articulación del Gobierno y los congresistas con la sociedad civil y los medios de comunicación.

\section{Obstáculos}

- Hay grupos de oposición a las reformas, fundamentalmente representados por algunos legisladores, que buscan establecer nuevamente la facultad del Senado de designar y ratificar a los jueces. La variante es que el Congreso ratifique los jueces que designe el Consejo Nacional de la Magistratura.

- También hay opiniones desde el Ejecutivo que plantean la necesidad de reducir las atribuciones de la Suprema Corte de Justicia, alegando el exceso de funciones administrativas y jurisdiccionales que 
ostenta desde las reformas constitucionales de 1994, pero que hasta ahora ha demostrado incapacidad para asumir.

\section{$\underline{\text { Poder Legislativo }}$}

\section{Recomendaciones}

- Es necesario promover iniciativas encaminadas a institucionalizar y modernizar el Congreso Nacional. Las reformas deben realizarse en tres áreas principales: la legislativa, la administrativa y la relación del Congreso con la sociedad.

- En la actividad legislativa se requiere de una reforma que haga efectivos los reglamentos vigentes y que facilite los trabajos de las comisiones, y fomente la investigación y la asesoría.

- En el área administrativa conviene impulsar cambios en tres áreas básicas: recursos humanos, que comprende todo el personal del Congreso y toca puntos tan fundamentales como la creación de la carrera administrativa congresional; el aspecto financiero y el mantenimiento de la planta fisica.

- Con el inicio del proceso de institucionalización del Congreso, se deben impulsar programas que permitan una mayor relación de los congresistas con la sociedad en general. Esto abarca la comunicación de los legisladores con los ciudadanos, relaciones públicas, programas de educación a la población para dar a conocer las funciones y actividades del Congreso y su importancia para el sistema democrático.

\section{Estrategias a seguir}

- Implementación de un programa de asesoría profesional especializada a los congresistas con el objetivo de fortalecer la función de los legisladores y coadyuvar en el diseño de las políticas a seguir por el Congreso.

- Establecimiento en el Congreso de la infraestructura tecnológica que dé soporte a un sistema informático sobre el estado de los proyectos 
de leyes, agendas del día, transcripción de los debates, vistas públicas, actas de comisiones y reuniones importantes; además, un sistema de votación electrónica y correo electrónico.

- Reorganización y sistematización de los archivos del Congreso. Debe contratarse un experto en el área de archivo a fin de que realice un estudio de la situación de los archivos y se inicie la reorganización y automatización de los expedientes.

- Una Comisión Mixta de legisladores deberá gestionar la cesión de otro edificio cercano al Congreso para que se puedan ampliar las instalaciones y el trabajo de las comisiones.

- Los departamentos de las comisiones deben ser elevados de categoría y dotados de personal suficiente y capacitado para realizar sus funciones.

- Para obtener la autonomía financiera del Congreso es necesario negociar con el Ejecutivo la apertura de una cuenta donde se deposite mensualmente la duodécima parte del presupuesto aprobado para cada Cámara y éstas puedan hacer uso de los recursos; reformar la Ley Orgánica de Presupuesto de 1969 para establecer la independencia económica del Congreso; $y$, finalmente, establecer a nivel constitucional la independencia económica del Congreso. Deberá crearse una comisión de presupuesto que dé seguimiento al uso de los fondos.

- Crear una oficina de orientación y servicio al público que permita una mayor relación entre el Congreso y la ciudadanía. En esta oficina se instalaría una línea telefónica gratuita y un buzón de sugerencias para recibir y tramitar las inquietudes ciudadanas.

- Creación de oficinas congresionales provinciales y de programas de educación ciudadana, que se correspondan con el programa de descentralización y modernización del Estado.

\section{Oportunidades}

- La diferenciación cada vez mayor de las funciones del Ejecutivo y el Legislativo al controlar distintos partidos cada uno de estos Pode- 
res Públicos, crea la posibilidad de que los legisladores se motiven a reformar el Congreso para ejecutar una mejor labor legislativa. Una labor legislativa más eficaz tendría consecuencias electorales positivas para los partidos con representación congresional

- Existen instituciones donantes interesadas en la modernización del Congreso dominicano, entre ellas, el Banco Interamericano de Desarrollo, el Banco Mundial, y los gobiemos de Francia y España. Esto facilita el acceso a recursos financieros y técnicos para ejecutar las reformas.

\section{Obstáculos}

- El principal obstáculo para la reforma del Congreso ha sido la falta de decisión para modernizar las estructuras, cambiar las normas y reglamentos internos, y mejorar la tecnología para que ayude a cumplir mejor la función legislativa.

- El personal del Congreso se ha acostumbrado a operar en un ambiente de precariedad organizativa y tecnológica, por lo cual podría esperarse de su parte una resistencia a los cambios. También habría que agregar que parte del personal del Congreso carece de la formación profesional adecuada para desear los cambios o adaptarse a ellos.

\section{Municipio y Poder Local}

\section{Recomendaciones}

- Se propone una descentralización basada en la transferencia de poder desde el Gobierno Central hacia los municipios y desde los municipios hacia la ciudadanía. Esto incluye el fortalecimiento de la personalidad jurídica de la provincia y el municipio, la democratización de las decisiones del cabildo, la descentralización financiera y ejecutiva.

- La transferencia de poder hacia el municipio debe acompañarse de una modernización del Gobierno Municipal, que incluye la reestructuración administrativa, la capacitación del personal, y una comunicación eficaz con la ciudadanía. 
- La descentralización y modernización municipal deben sustentarse en una mayor participación de la ciudadanía en los asuntos municipales, con el objetivo de aumentar los niveles de eficiencia del Gobiemo Municipal, promover el consenso en la toma de decisiones y fomentar una cultura democrática.

- La reforma municipal debe contemplar una reestructuración de la división geopolítica basada en una distribución poblacional coherente con el espacio territorial. En la actualidad los municipios difieren substancialmente en su tamaño y estructura. Es necesario adecuar la división geopolítica y electoral a esa diversidad.

\section{Estrategias a seguir}

- Es prioritario hacer más eficientes los servicios públicos que son responsabilidad de los ayuntamientos e impactar significativamente en la calidad de vida de la población.

- La descentralización y modernización de los municipios depende de la urgente aplicación de la Ley 140, que facilita los recursos financieros para la ejecutoria a nivel municipal, y del traspaso del cobro de impuestos a los municipios. Hay que contemplar posteriormente la elaboración de una Ley Orgánica de Municipios que establezca una definición modema del Municipio, su función, estructura de gobierno, organización, y funcionamiento.

- La modernización del Gobiemo Municipal requiere de la revisión de la actual estructura administrativa municipal para adecuarla a los objetivos de la descentralización y las necesidades municipales. Deben actualizarse los impuestos municipales y mejorarse el procedimiento de cobro, revisarse las funciones de los ayuntamientos, e implementarse mecanismos adecuados para la participación de la ciudadanía.

- Para el buen funcionamiento del Municipio también hace falta la capacitación del personal. Esta capacitación puede estar coordinada por la Liga Municipal Dominicana (LMD), aprovechando los servicios de las universidades, ONGs, entidades gubernamentales, y agencias internacionales. 
- El éxito de la reforma municipal depende de su aceptación y comprensión en las instancias de gobierno y la población. Es importante difundir las experiencias existentes en América Latina, como es el caso de Bolivia y la República Dominicana en materia de descentralización y modernización del Municipio.

- Para facilitar la participación ciudadana se recomiendan las siguientes acciones: un registro municipal de organizaciones de base, cabildos abiertos, consejos consultivos municipales, una ley de participación comunitaria, y plebiscitos municipales.

- Se propone la creación de distritos electorales municipales, que los candidatos a regidores se presenten por distrito electoral y sean elegidos por los votos de ese distrito para representar ese distrito en el cabildo.

- Para resolver los problemas administrativos que derivan de municipios de diversos tamaños, se propone establecer un tope mínimo y máximo de habitantes por municipio, o establecer diferentes categorías de municipios según la población con su adecuada forma de descentralización.

- El Distrito Nacional debe ser dividido en varios municipios, aunque se cree la figura del Alcalde de la ciudad para representar el conjunto de los municipios.

- El proceso de reforma municipal puede comenzarse por la selección de algunos municipios "experimentales", que sirvan para probar las propuestas.

\section{Oportunidades}

- Hay niveles de receptividad en la sociedad civil en torno a la necesidad de la descentralización municipal. Varias organizaciones han elaborado propuestas de reforma, entre ellas, la Unión de Vecinos Activos (UVA), el Comité para la Defensa de los Derechos Barriales (COPADEBA), los partidos mayoritarios en sus programas de gobierno, la Fundación Siglo XXI, y el Grupo de Acción por la Democracia. 
- Las agenciasinternacionales apoyan las medidas de descentralización y modernización municipal. Es conocido el proyecto del PNUD en coordinación con la Secretaría Técnica de la Presidencia y la Liga Municipal Dominicana.

\section{Obstáculos}

- Resistencias por parte de los Cabildos a la implementación de controles de supervisión. Por otra parte, las prácticas actuales de ineficiencia en los Ayuntamientos puede crear resistencia de parte de los empleados que se sientan amenazados por las innovaciones.

- La resistencia de las clientelas tradicionales del Ayuntamiento, que encuentran dificultad en superar prácticas como las prebendas y el soborno.

- Las medidas de descentralización pueden recibir escaso apoyo del Ejecutivo, sobre todo antes de las elecciones congresionales y municipales de 1998.

- Algunos partidos podrían oponerse a la reorganización geopolítica de los municipios con la que perderían municipios, así como a la redefinición de la elección de los regidores.

- La propuesta de creación de municipios experimentales puede generar controversias con los municipios no elegidos incluidos en el programa experimental. La posibilidad de ser incluidos más adelante puede ayudar a obviar esta dificultad.

\section{Administración Pública y Servicio Civil}

\section{Recomendaciones}

- El profundo arraigo en la cultura política dominicana del clientelismo como recompensa eleccionaria y el condicionamiento de la Administración Pública por la política partidaria y su alarmante deterioro requieren de acciones estratégicas que hagan más participativo y democrático el sistema político para así promover una adecuación 
cultural hacia nuevos valores éticos, político-administrativos e institucionales en todos los sectores sociales.

- La organización del sistema dominicano de planificación del desarrollo no ha tenido mucha significación en el pais. Su urgente actualización y modernización puede coadyuvar al fortalecimiento del sistema político.

- La Administración del Estado dominicano ha crecido de manera casuística y por agregación, sin responder a un estudio científico. Se requiere de un reordenamiento orgánico, procedimental y de sistemas de la Administración Pública.

- El Servicio Civil es un viejo reclamo de los dominicanos. La implementación y puesta en marcha de la reforma estructural del Estado con miras a su modernización y el mejoramiento de los servicios públicos, a través de la efectiva aplicación de la Ley de Servicio Civil y Carrera Administrativa, son objetivos que requieren de acciones inmediatas y concertadas.

\section{Estrategias a seguir}

- En referencia a la Administración Pública, modificar el Art. 55 de la Constitución en lo concerniente al nombramiento de los servidores públicos, de manera que el Presidente de la República sólo designe a los titulares, de acuerdo a la Ley $14 / 91$; restablecer la facultad de los Secretarios de Estado de refiendar los actos del Poder Ejecutivo, y fortalecer la capacidad decisoria de los Secretarios de Estado.

- Para logar la transformación de la cultura política y administrativa imperante, diseñar un Código de Ética de la Administración Pública y elaborar un plan contra la comupción; crear en cada organismo del Ejecutivo una unidad de información al público; y crear instrumentos de comunicación interna en la Administración Pública.

- Diseñar planes regionales de desarrollo nacional con la participación del Municipio y definir la sectorialiadad de la Administración Pública. 
- En lo referente al reordenamiento y modernización del sistema de control financiero, introducir el uso de sistemas, procedimientos y métodos de naturaleza contable-financiera que agilizarian los trámites; y dirigir y coordinar las labores de control interno de las instituciones del Estado, en cuanto al manejo de los fondos públicos.

- Realizar un estudio sobre la organización del Poder Ejecutivo, incluidas las Secretarías de Estado y sus dependencias, así como los organismos autónomos, para identificar su naturaleza y la duplicidad de funciones e inoperancia de instituciones que no cumplen con sus cometidos.

- Para adecuar y modernizar la legislación de la Administración del Estado, se requiere de la actualización de la Ley Orgánica de Secretarías de Estado No. 4378 de 1956; la modificación de los Arts. 50 y 51 de la Ley Orgánica de Presupuesto del Sector Público No.531 de 1966; y suprimir mediante legislación las cuentas especiales de manera que todo el ingreso del Estado sea depositado en el Fondo General de la Tesorería Nacional.

- Modernizar el sistema de Pensiones y Jubilaciones del Estado para que ofrezca mayor seguridad y cobertura económica a los servidores públicos retirados.

- Para desburocratizar la Administración Pública, lograr mayor agilidad y eficiencia en la prestación de servicios públicos, simplificar los trámites a los usuarios, humanizar la prestación de servicios, y concientizar a la ciudadanía de su responsabilidad cívica de participar en el mejoramiento de la Administración Pública.

- En cuanto al Servicio Civil se requiere que el Presidente de la República, instruya a sus ejecutivos acerca del contenido de la Ley de Servicio Civil y Carrera Administrativa No.1491 de 1991; fortalecer a la ONAP como órgano ejecutor de las disposiciones de la Ley de Servicio Civil y Carrera Administrativa y de su Reglamento de Aplicación No.81-94 de 1994; reordenar las Oficinas de Personal de las instituciones públicas; designar como Encargados de Oficinas a funcionarios que reúnan los requisitos para los cargos ; realizar todas las designaciones públicas dentro del marco de la Ley de Servicio Civil 
y Carrera Administrativa, y expandir los alcances de la Ley a todas las dependencias públicas.

- Desarrollar el Registro Nacional de Servidores Públicos, realizar un estudio de la estructura salarial en el sector público, y proveer al Instituto Nacional de la Administración Pública (INAP) de los recursos financieros necesarios para realizar los programas de capacitación e investigación necesarios para la modernización del Estado.

\section{Oportunidades}

- Existen ya la Ley de Servicio Civil y Carrera Administrativa aprobada en 1991, y el Reglamento para su implementación aprobado en 1994. La existencia de esta legislación deberá facilitar el proceso de reforma administrativo.

- Hay ambiente social e institucional (Iglesia, universidades, prensa) a favor de una ética de la función pública.

- Expectativas de importantes sectores de la sociedad dominicana de que mejoren los servicios públicos.

- La modernización del Estado requiere la modernización de la Administración Pública.

\section{Obstáculos}

- En la Administración Pública dominicana existen prácticas nocivas que son expresión de una cultura política donde ha predominado el autoritarismo, el clientelismo y el caudillismo. De ahí la resistencia a la modemización de parte de los servidores públicos, los partidos políticos y el Gobiemo Central.

- El Gobierno ha destinado recursos financieros muy limitados para el entrenamiento del personal administrativo.

- Los resultados políticos de una reforma administrativa no son necesariamente observables en el corto plazo. 


\section{Sociedad Civil}

\section{Recomendaciones}

- El propósito principal de la reforma debe ser propiciar la articulación de los diversos actores que conforman la sociedad civil de manera que éstos superen su dispersión, se evite la exclusión en los procesos que se generan en su interior, y se alcancen niveles de maduración que coloquen a la sociedad civil en mejor condición de participar en el proceso social. Esto implica la creación de espacios de participación y articulación en los cuales los actores de la sociedad civil puedan encontrarse y concertar.

- Se debe enfatizar el fortalecimiento de la sociedad civil en sus instituciones específicas, y en su capacidad de acción coordinada de manera que sea de más en más un factor relevante en el funcionamiento de la vida democrática.

- Diseño y aprobación de una Ley de Participación Popular, partiendo de la experiencia boliviana

\section{Estrategias a seguir}

- Creación de espacios de concertación y participación en el debate de la agenda nacional, mediante la celebración de congresos, jomadas y foros que sirvan de encuentro a las organizaciones de base, a las instituciones de un mismo sector de intervención, y a las organizaciones intermedias a nivel regional y nacional.

- Estimular la creación de espacios permanentes de coordinación que surjan por iniciativa de un conjunto de organizaciones e institucionesdecididasa agruparsepara la realización máseficaz de suspropósitos.

- Las áreas más importantes en que debe participar la sociedad civil dada la situación actual de la sociedad dominicana, son los consejos regionales y municipales de desarrollo, la selección de los jueces de la Junta Central Electoral, la observación electoral, la selección del Consejo Nacional de la Magistratura, y de la Asamblea Constituyente, en caso de realizarse para modificar la Constitución. 
- Estudio, revisión y adecuación de la Ley 520 que data de 1920. Se requiere de una revisión que tome en cuenta la práctica social vigente.

\section{Oportunidades}

- Las exitosas experiencias recientes de participación de la sociedad civil constituye un referente importante para que se consideren las reformas.

- La disposición de participar en la reforma que tienen las organizaciones sociales.

- La percepción del presente como una oportunidad para propiciar cambios en la sociedad dominicana.

- Los niveles de organización y el número y diversidad de agrupaciones logradas por la sociedad civil, en los últimos años.

\section{Obstáculos}

- Inclinación de los partidos políticos y los gobiernos a concebir la sociedad civil como potencial usurpadora de la función de los partidos.

- La atomización y desconfianza de los propios sectores de la sociedad civil que dificultan las reformas.

- El diferente grado de desarrollo logrado que se advierte entre las distintas organizaciones de la sociedad civil dominicana.

\section{Medios de Comunicación}

Losmedios de Comunicación Social(MCS) son en la actualidad instrumentosfundamentalesdel desarrollo democrático. Por supropia definición, la comunicación implica puesta en común de los hechos queimportan ala colectividad. Estosmedios son mecanismosimprescindibles para estimular la participación política en una sociedad con 
una población creciente, concentrada en pocos núcleos urbanos que reúnen más del $60 \%$ de los habitantes.

Es universalmente aceptado que los medios de comunicación tienen un papel importante que desempeñar en la promoción de las normas de convivencia democrática.

El análisis del papel de los medios en el desarrollo del sistema político yen el fortalecimiento delasinstituciones democráticas parte de la concepción clásica que considera la libertad de expresión, el derecho a informary ser informado y el libreacceso a la información, como elementos fundamentales del sistema democrático.

Almismotiempo, estavisión dela información como ingrediente central de la democracia plantea como exigencia el pluralismo de la oferta informativa y la aceptación de una premisa ética y una visión de servicio público en los individuos e instituciones que manejan los medios, como contrapeso y legitimación de su función como comunicadores.

\section{Recomendaciones}

- Involucrar a los segmentos del sector de la comunicación interesados y hacerlos participes de la orientación de los programas.

- Participación de las instituciones del sector

- Involucramiento de dirigentes empresariales de otros sectores en el proceso.

- Motivar un grupo informal de comunicadores interesados en la temática.

- Difusión permanente de información sobre la marcha de las reformas en otros países. 


\section{Estrategias a seguir}

- A corto plazo

- Programa para promover la participación de los MCS

- Difusión sistemática de información de alta calidad sobre las reformas.

- A mediano plazo

- Programa de actualización legislativa

- Programa para promover el debate y la investigación sobre la realidad de los MCS y mejorar la formación de recursos humanos.

\section{Oportunidades}

- Desarrollo de un período de competencia en el sector de los MCS por los cambios que se están introduciendo.

- Incursión de nuevos grupos económicos en el sector de la comunicación.

- Posición formalproclamada por los MCS de apoyo a los cambios y modemización de la sociedad.

- Actitud crítica en segmentos importantes de comunicadores.

\section{Obstáculos}

- Hipersensibilidad de propietarios y directores de medios a cualquier acción que pueda parecerle de supervisión o intromisión en su ámbito de acción.

- Dinámica de trabajo absorbente existente en los medios.

- Falta de tradición en el análisis público de la realidad de los medios de comunicación

- Bajo nivel profesional y carencia de recursos para los programas de formación de comunicadores en las universidades.

- Renuencia tradicional de los MCS a dedicar recursos y facilitar la superación profesional de los comunicadores. 


\section{UNA ORGANIZACIÓN DE LAS ESTRATEGIAS DE REFORMA.}

Para impulsar el proceso de reforma política se requiere de una organización de las estrategias de reforma. El análisis del estado actual del sistema político dominicano, las propuestas de reforma realizadas por área y las prioridades establecidas requieren de algunas sugerencias para la implementación del proyecto de reforma política.

En la organización de las prioridades de reforma se identifican tres temas fundamentales que cubren las distintas áreas del sistema político dominicano:

- La Modernización Administrativa

- La Actualización de la Legislación Orgánica

- La Reforma Constitucional

La modernización de la administración pública debe ser la prioridad de todos los Poderes del Estado. Para impulsar estas reformas se necesita de voluntad política y vocación democrática. En la práctica se requiere de una revisión racional de los sueldos en la administración pública, una evaluación de la infraestructura física y tecnológica, y la asignación de recursos destinados especialmente a alcanzar la modernización administrativa.

Para alcanzar este objetivo, el Poder Ejecutivo debería destinar un porcentaje sustancial del presupuesto de sus respectivas dependencias (Presidencia de la República, secretarías de Estado, gobiemos provinciales y municipales y organismos autónomos) con el propósito de crear un Fondo Especial para la Modernización Administrativa. Esta práctica debería ser igualmente aplicada por el Congreso y la Judicatura. 
Para alcanzar este objetivo el gobiemo dominicano cuenta con el apoyo financiero de las agencias internacionales. Para ampliar las oportunidades de captación de recursos y asistencia internacional, y para coordinar y supervisar los programas de modernización administrativa, el Secretariado Técnico de la Presidencia en coordinación con la Comisión para la Reforma del Estado debería crear una Unidad Técnica Especializada que promueva y coordine estos trabajos.

La reforma política dominicana requiere también de cambios en las leyes orgánicas que regulan la actividad del Estado, los partidos políticos y la sociedad civil. La realización de este objetivo constituye otra prionidad en las distintas áreas del sistema político, ya que, la revisión de las leyes orgánicas se hace necesaria para adecuarlas a los desafios que conlleva la consolidación democrática y la inserción de la República Dominicana en el nuevo modelo económico intermacional.

Las reformas dirigidas a la aprobación de una legislación funcional y moderna deben emerger de las necesidades de las distintas instancias del sistema político, en base a las experiencias acumuladas y las demandas sentidas. Las oficinas de consultoría jurídica de los distintos poderes del Estado podrian, en los casos correspondientes, y en coordinación con la Comisión Presidencial de Reforma y Modernización del Estado, asesorar a las distintas instituciones donde se requiere de revisiones a las leyes orgánicas y sus reglamentos. Un acuerdo interpartidario es crucial para impulsar estas reformas de una manera rápida y eficaz.

La necesidad actual de reformar la Constitución, deriva de que los cambios que se introdujeron en 1994 trastocaron la organización y el funcionamiento del sistema político dominicano, sin dar una respuesta integral a la necesidad de reformarlo para hacerlo más democrático y funcional. Esta experiencia señala la necesidad de que se realice una nueva reforma constitucional en el momento adecuado y con el tiempo suficiente para planificarla y conducirla democráticamente.

$\mathrm{La}$ experiencia constitucional de muchos países indica que en un proceso de reforma constitucional hay dos resultados posibles. Una constitución clara y de lineamientos generales que establezca las bases fundamentales del sistema político y los derechos ciudadanos, o una 
constitución sobrecargada que intente dar respuesta a las demandas específicas de los distintos sectores políticos y sociales.

La experiencia de América Latina en reforma constitucionalmuestra una abundancia de constituciones sobrecargadas de disposiciones que, con frecuencia, son vulneradas o resultan inoperantes. La experiencia de lospaíses con larga tradición democrática (Estados Unidos e Inglaterra, si bien el último carece de constitución) muestra lo contrario.

Con esta evidencia histórica, la reforma constitucional dominicana debería producir un texto claro, de lineamientos generales y factible de ser adaptado a las condiciones cambiantes de la sociedad democrática. Debería también resultar de un proceso amplio de consulta, ya sea por vía de una Asamblea Constituyente, o realizada por el Congreso con las adecuadas convocatorias y vistas públicas que cuenten con la participación de los partidos políticos y la sociedad civil.

Para realizar esta compleja e importante tarea de revisión constitucional, se sugiere la formación de una Comisión para la Reforma Constitucional con representantes de los partidos políticos mayoritarios y minoritarios, de la sociedad civil organizada en sus diferentes instancias y de expertos en materia constitucional Esta Comisión podría ser convocada por el Presidente de la República o por el Congreso, pero debería ser independiente de los poderes públicos. La tarea inicial de esta Comisión sería la de establecer los objetivos básicos a alcanzar y el calendario de trabajo que culnine en una reforma constitucional antes del año 2000.

Para facilitar la compresión y retención de los elementos fundamentales de este ejercicio de planificación estratégica, presentamos los siguientes cuadros sinópticos. 


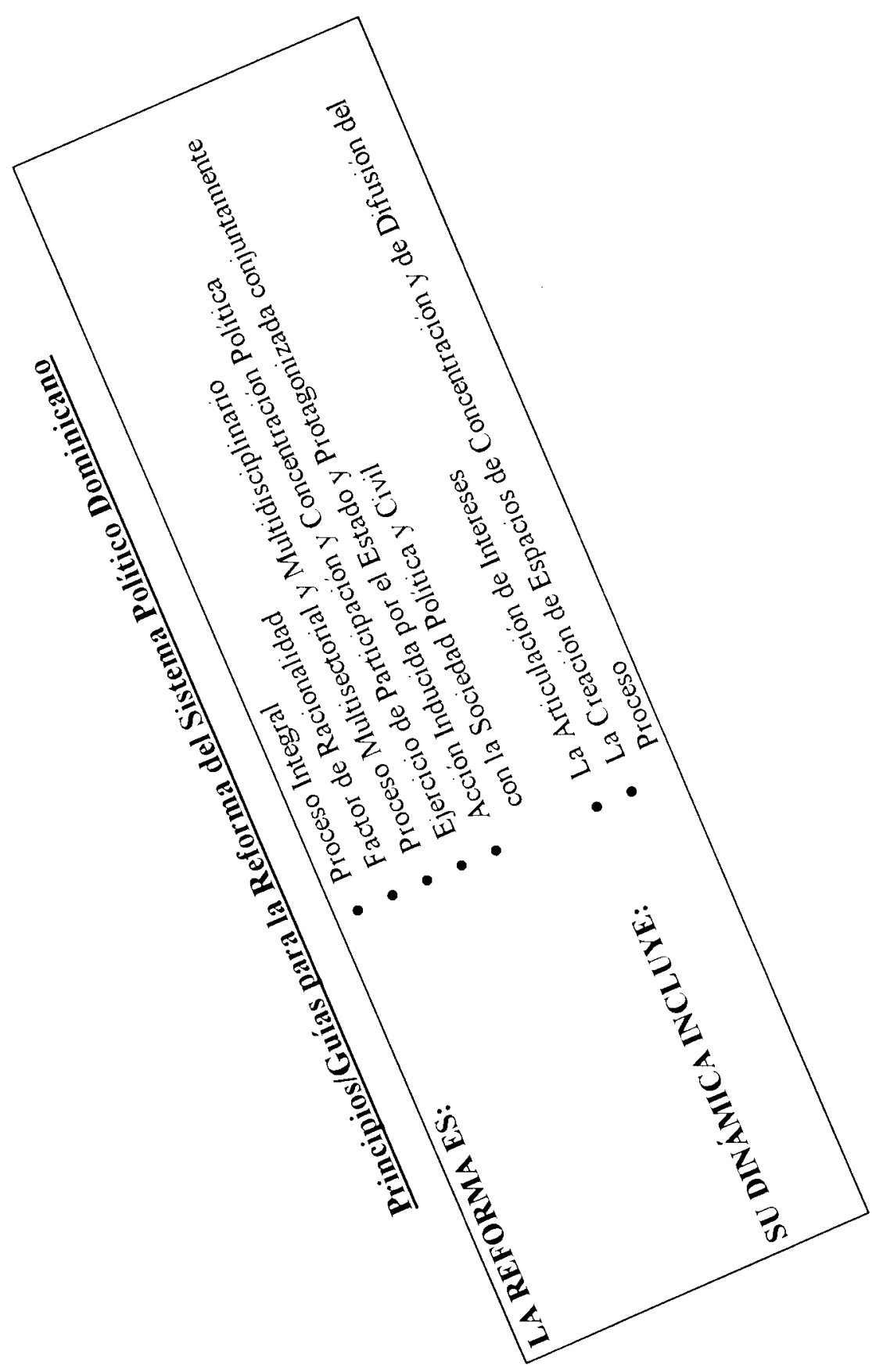

76 
La Reforma Política:

Entre la Oportunidad y los Obstáculos

\begin{tabular}{|c|c|}
\hline $\begin{array}{l}\text { Oportunidades Favorables } \\
\text { - El cambio de Gobierno en agosto de } \\
1996 \\
\text { - Las iniciativas del presidente } \\
\text { Fernández } \\
\text { - El nuevo contexto de globalidad y la } \\
\text { necesidad de mantenerse en la } \\
\text { economía mundial } \\
\text { - La necesidad de reformas sentida por } \\
\text { la propia sociedad politica, sumada a } \\
\text { su gran receptividad en el seno de la } \\
\text { sociedad civil } \\
\text { - El fuerte apoyo por parte de los } \\
\text { organismos internacionales y gobiernos } \\
\text { extranjeros amigos } \\
\text { - La abundancia de proyectos de Ley y } \\
\text { planes de reforma preparadas en los } \\
\text { últimos años. } \\
\text { - La existencia de instituciones de } \\
\text { sociedad civil (ONGs, Fundaciones) } \\
\text { con experiencias en la promoción de } \\
\text { reformas } \\
\text { Existen ya leyes aprobadas (Servicio } \\
\text { Civily Carrera Administrativa y sus } \\
\text { reglamentos)e instituciones } \\
\text { conformadas (Consejo Nacional de la } \\
\text { Magistranra) que viabilizan la } \\
\text { implantación de reformas. } \\
\text { - La consecuencia de que, si se } \\
\text { desaprovecha la presente "Ventana de } \\
\text { Oportunidad", el resultado puede se de } \\
\text { graves consecuencias para la } \\
\text { democracia. }\end{array}$ & $\begin{array}{l}\text { Obstáculos } \\
\text { - La vigencia del tradicionalismo, el } \\
\text { conservacionismo y la resistencia al } \\
\text { cambio } \\
\text { - La cuitura política que privilegia el } \\
\text { autoritarismo, el caudillismo y la } \\
\text { centralización del poder en la figura del } \\
\text { presidente "Providencial" } \\
\text { - El peso de intereses particulares y } \\
\text { grupa les que resultarian perjudiciales } \\
\text { para las reformas. } \\
\text { - El fantasma de la "ingerencia } \\
\text { extranjera" supuestamenteacechando } \\
\text { tras el apoyo internacional a la } \\
\text { reforma. } \\
\text { - Debilidad coyuntural del Poder } \\
\text { Ejecutivo ante unCongreso dominado } \\
\text { por la oposición hasta 1998 por lo } \\
\text { menos. } \\
\text { - Posibilidad de marginalización de la } \\
\text { reforma política en favor de otras } \\
\text { iniciativaso por comparaciones } \\
\text { políticas ineludibles. } \\
\text { - Competencia deotras Reformas } \\
\text { (económicas y sociales) a la agenda de } \\
\text { Reforma Política. } \\
\text { - Atomización de la sociedad civil y } \\
\text { disputas entre exponentes de la misma. }\end{array}$ \\
\hline
\end{tabular}


BOSQUEJO DE UNA ESTRATEGIA PARA LA REFORMA POLÍTICA

\section{Modernización de la Administración Pública.}

\section{PASOS FUNDAMENTALES}

- A nivel Central

- Poder Ejecutivo

- Legisativo

- Jucicial

- A nivel Local

- Regional

- Provincial

- Mumicipal

[Puede emprenderse de inmediato, sin nueva legislación]

\section{HECHOS REALIDAD MEDIANTE...}

- Decisión de un \% de los distintos presupuestos (Presidencia, Secretarias de Estado, Organismos Autónomos, Gobiemos Provinciales y Mumicipales, Congreso, Judicatura...) a un Fondo Especial para la Modemización Administrativa.

- Creación, œ STP/CPRME, de una Unicad Técnica Especializada de Coordinación para la Modemización Administrativa.

- Solicitud de apoyo técnico y/o financiamiento a los organismos internacionales de financiamiento (PNUD, UE, BM. BID, USAID...)

\section{A FIN DE OBTENER COMO RESULTADO..}

- Evaluación de la infraestructura fisica y tecnolóyca.

- Racionalización de los salarios de la Administración Pública.

- Modennzación de la administración, en sus diversas ramas, para maximizar su eficacia y eficiencia.

- Descentralización administrativa (devolución de atribuciones del poder central local.

- Hacer realidad la participación ciudadana, en particular al nivel local. 


\section{BOSQUEJO DE UNA ESTRATEGIA PARA LA \\ REFORMA POLÍTICA}

\section{Actualización de la Legislación Reguladora del Sistema Político}

\section{PASOS FUNDAMENTALES}

-Estado: $\quad-3$ Poderes (Ejecutivo, Legislativo, Judicial)

- Todo Nivel (Central, Local)

- Partidos Políticos

- Sociedad Civil

[Debe intentarse con el presente Congreso]

\section{HECHOS REALIDAD MEDIANTE...}

- Oficinas de consultoria juritica de los distintos poderes del Estado, en coordinación con CPRME, asesorando a las instituciones que requieran de revisión a sus leyes orgánicas y/o reglamentos.

- Acuerdo interpartidario amplio para impulsar rápida y eficazmente los cambios necesarios en la legislación.

- Consulta a, y participación real, de la Sociedad Civil

\section{A FIN DE OBTENER COMO RESULTADO...}

- Adecuar la legislación reguladora del sistema político (Estado, partidos, sociedad civil) a los desafios de la consolidación democrática y la inserción de la R.D. en el nuevo modelo económico munctial.

- Diseñar e implementar una Ley de Participación Popular que sirva de base legal para la incorporación de la sociedad civil en la conducción de los asuntos públicos.

- Diseñar y aplicar una Ley de Modemización de los Partidos Políticos, y de no ser esta flexible, buscar la aprobacón de la Reforma Electoral propuesta por la JCE (que contiene medidas impoirtantes para esos fines) entendiéndola como un Código Electoral. 
BOSQUEJO DE UNA ESTRATEGIA PARA LA

\section{REFORMA POLÍTICA}

\section{Reforma Constitucional}

\section{PASOS FUNDAMENTALES}

- O mediante Asamblea Constituyente (por elección popular)

- O por el Congreso (pero con amplia consulta con la sociedad civil)

[Debe emprenderse entre 1998 y 2000, por miciativa del Congreso elegido en 1998]

\section{HECHOS REALIDAD MEDIANTE...}

- Creación de una Comisión Nacional para la Reforma de Constitución

- Convocada por el Presidente y/o el Congreso, pero independiente de los poderes publicos .

- Compuesta por:

- Representantes de los partidos políticos mayoritarios y minoritarios.

- Representantes de la Sociedad Civil.

- Expertos en materia constitucional.

- Afin de : señalar objetivos báscos de la reforma,calendario de trabajo y metodología.

\section{A FIN DE OBTENER COMO RESULTADO...}

- Un texto constitucional con las siguientes caracteristicas:

- Claro

- Limitado a lineamientos generales

- Flexible, de forma que pueda adaptarse a las concticiones cambiantes de la nueva sociedad democratica. 